\title{
Reactions of Anodically Generated Methoxystilbene Cation \\ Radicals: The Influence of Ortho-Substituted Vinyl and \\ Formyl Groups
}

Kam-Weng Chong, Noel F. Thomas, Yun-Yee Low, and Toh-Seok Kam*

Department of Chemistry, Faculty of Science, University of Malaya, 50603 Kuala Lumpur,

Malaysia

Corresponding author’s e-mail address: tskam@um.edu.my 


\section{Table of Contents}

Page

1. ${ }^{1} \mathrm{H}$ and ${ }^{13} \mathrm{C}\left\{{ }^{1} \mathrm{H}\right\}$ NMR spectra of stilbenes

$\mathrm{S} 3-\mathrm{S} 16$

2. $\quad{ }^{1} \mathrm{H}$ and ${ }^{13} \mathrm{C}\left\{{ }^{1} \mathrm{H}\right\}$ NMR spectra of electrochemical oxidation products

S17 - S42

3. Cyclic voltammograms of stilbenes $\mathbf{1}$ and $\mathbf{3}$

S43

4. X-ray crystallographic analysis of $\mathbf{3 a}, \mathbf{3 b}$, and $\mathbf{6 a}$

S44

5. X-ray crystal data and structures

$\mathrm{S} 45-\mathrm{S} 47$ 


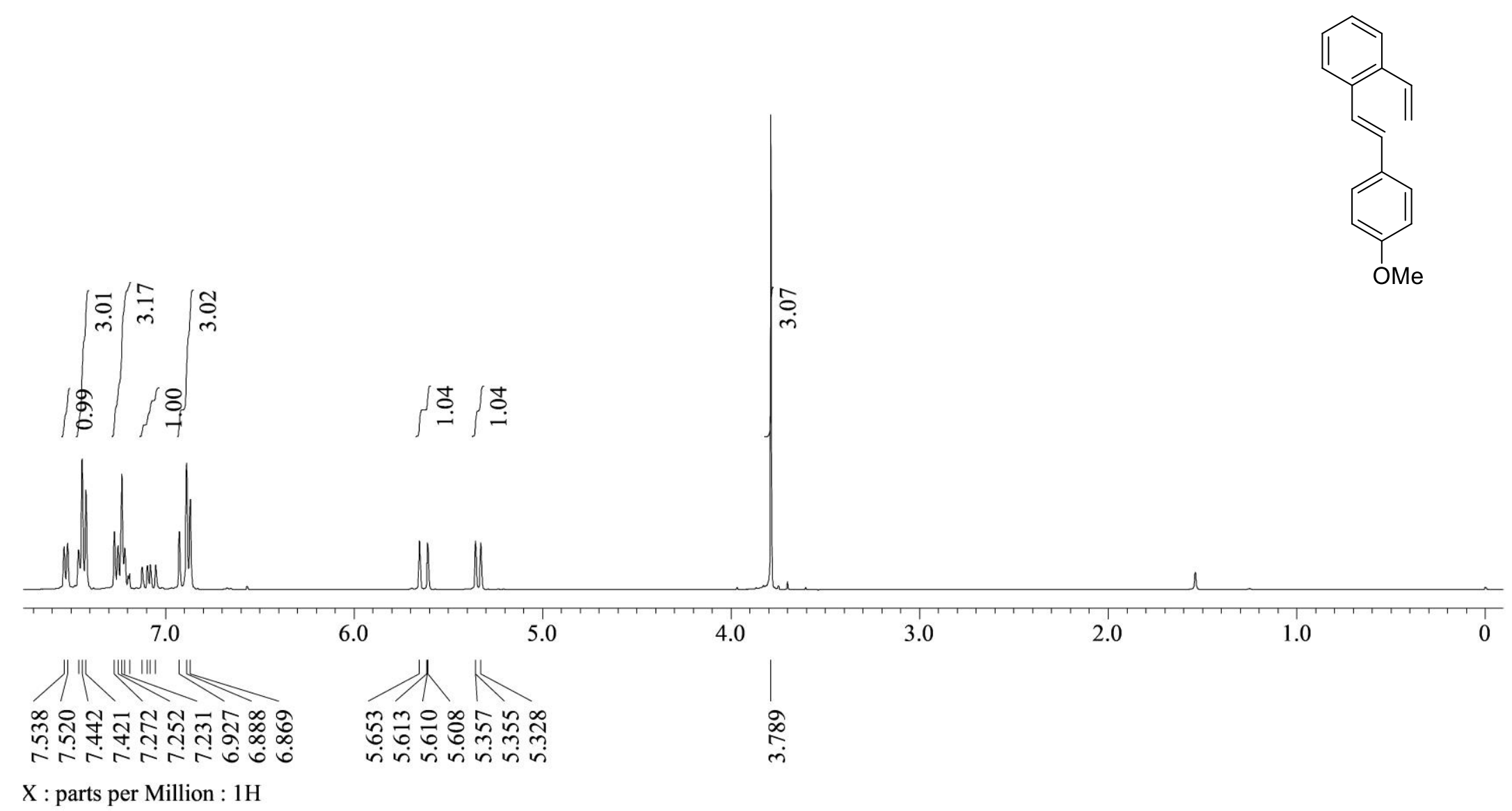

Figure S1. ${ }^{1} \mathrm{H}$ NMR $\left(\mathrm{CDCl}_{3}, 400 \mathrm{MHz}\right)$ spectrum of stilbene $\mathbf{1}$ 


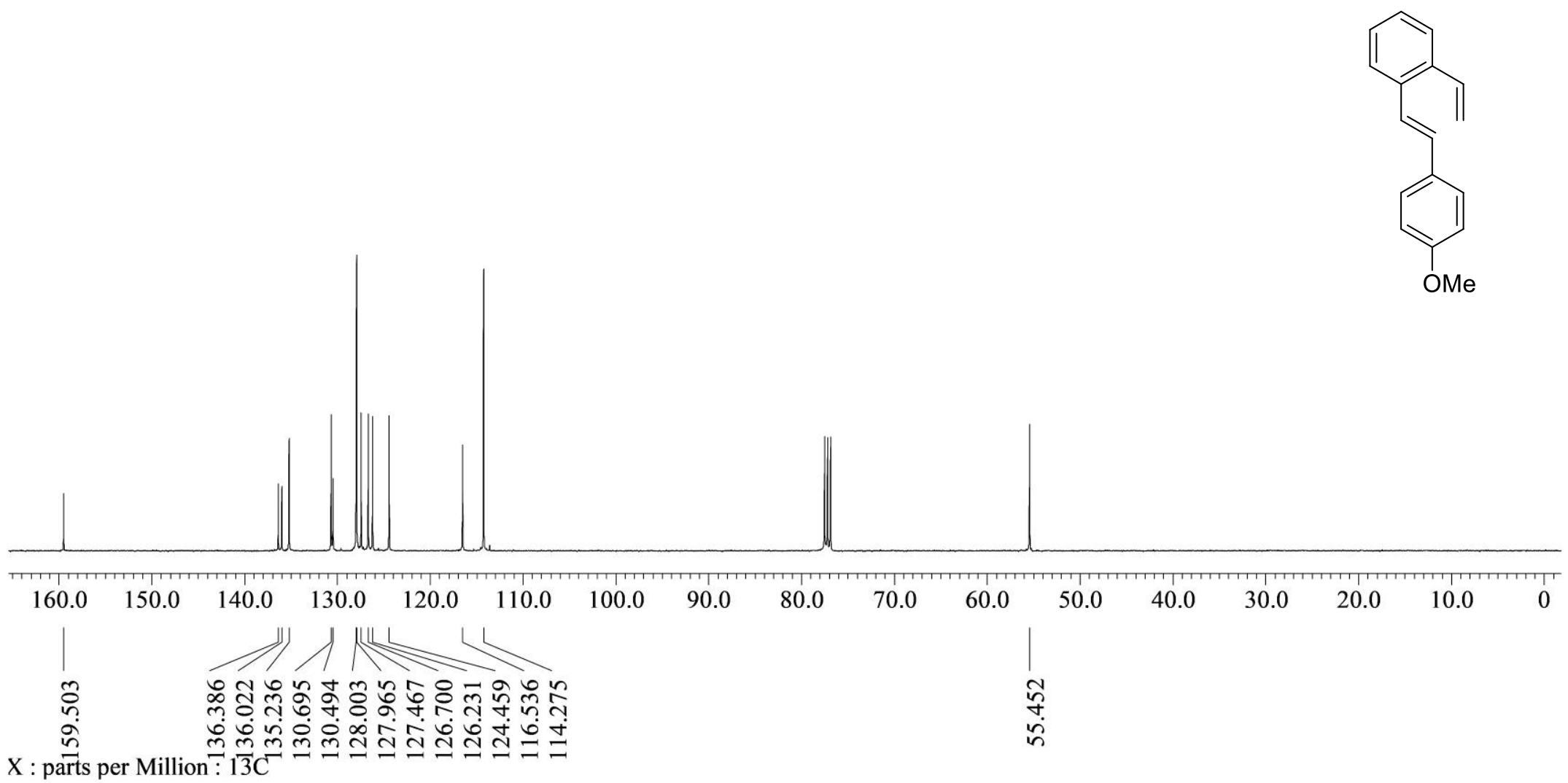

Figure S2. ${ }^{13} \mathrm{C}\left\{{ }^{1} \mathrm{H}\right\}$ NMR $\left(\mathrm{CDCl}_{3}, 100 \mathrm{MHz}\right)$ spectrum of stilbene $\mathbf{1}$ 


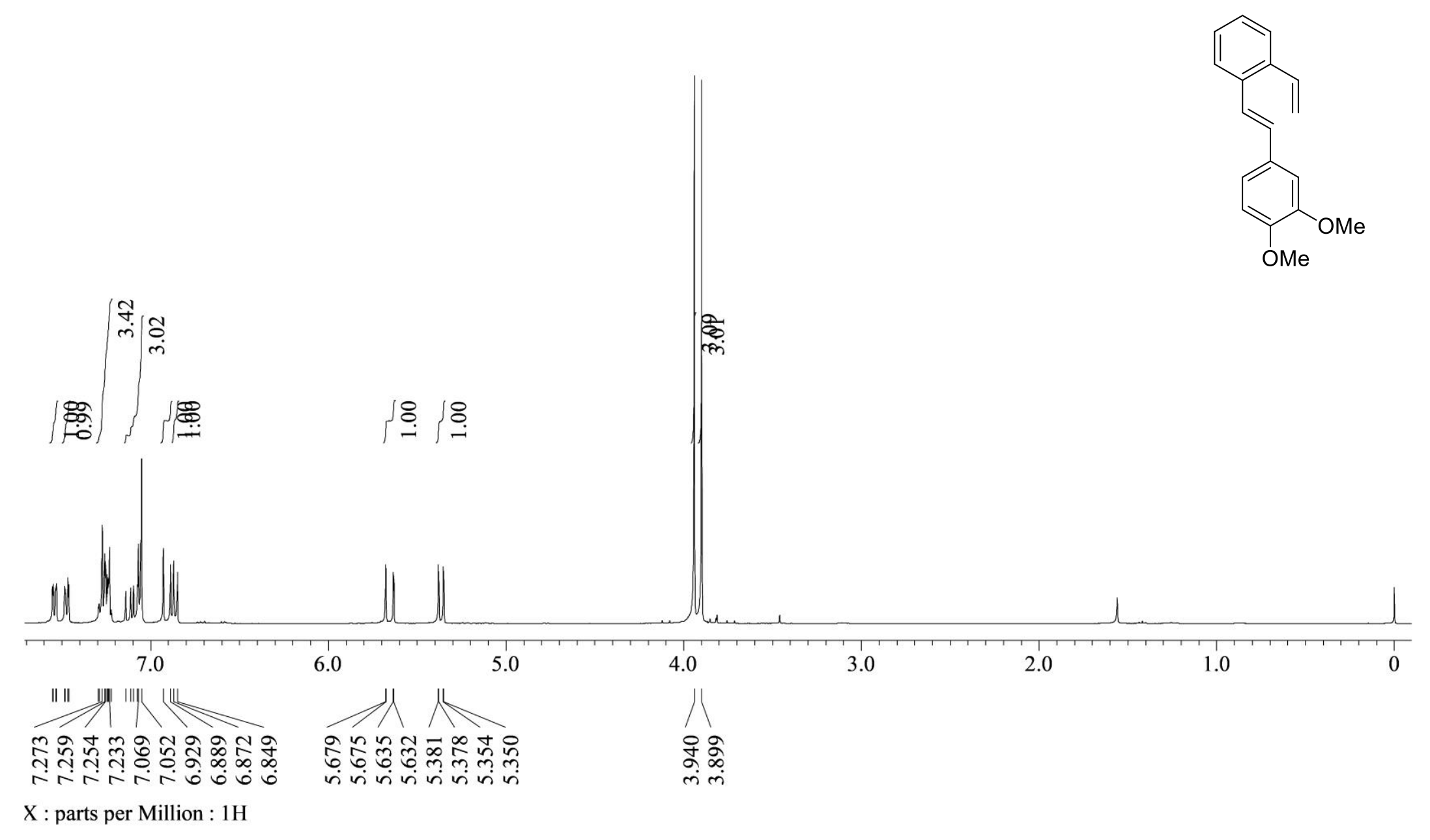

Figure S3. ${ }^{1} \mathrm{H}$ NMR $\left(\mathrm{CDCl}_{3}, 400 \mathrm{MHz}\right)$ spectrum of stilbene 2 


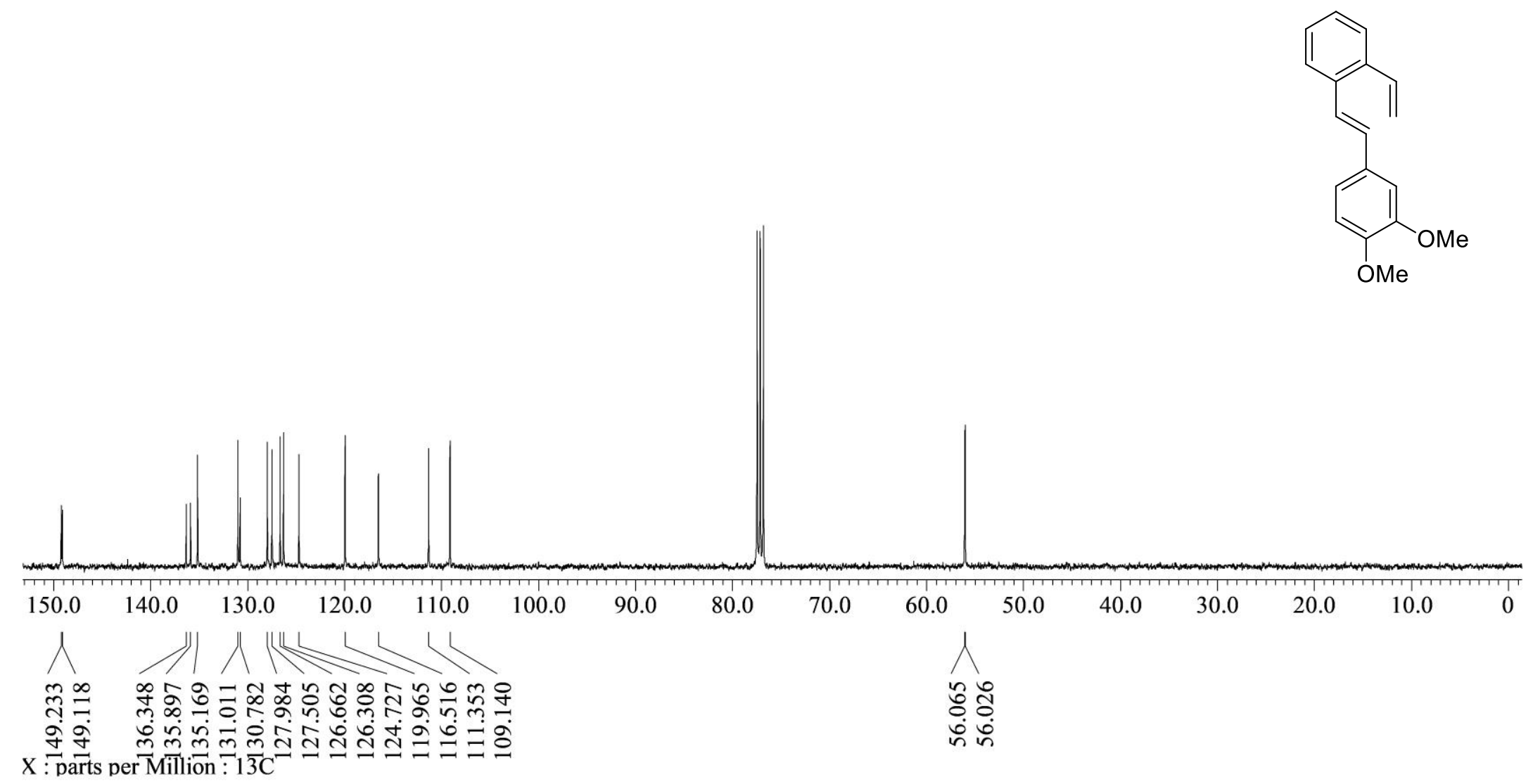

Figure $\mathrm{S} 4 .{ }^{13} \mathrm{C}\left\{{ }^{1} \mathrm{H}\right\}$ NMR $\left(\mathrm{CDCl}_{3}, 100 \mathrm{MHz}\right)$ spectrum of stilbene $\mathbf{2}$ 


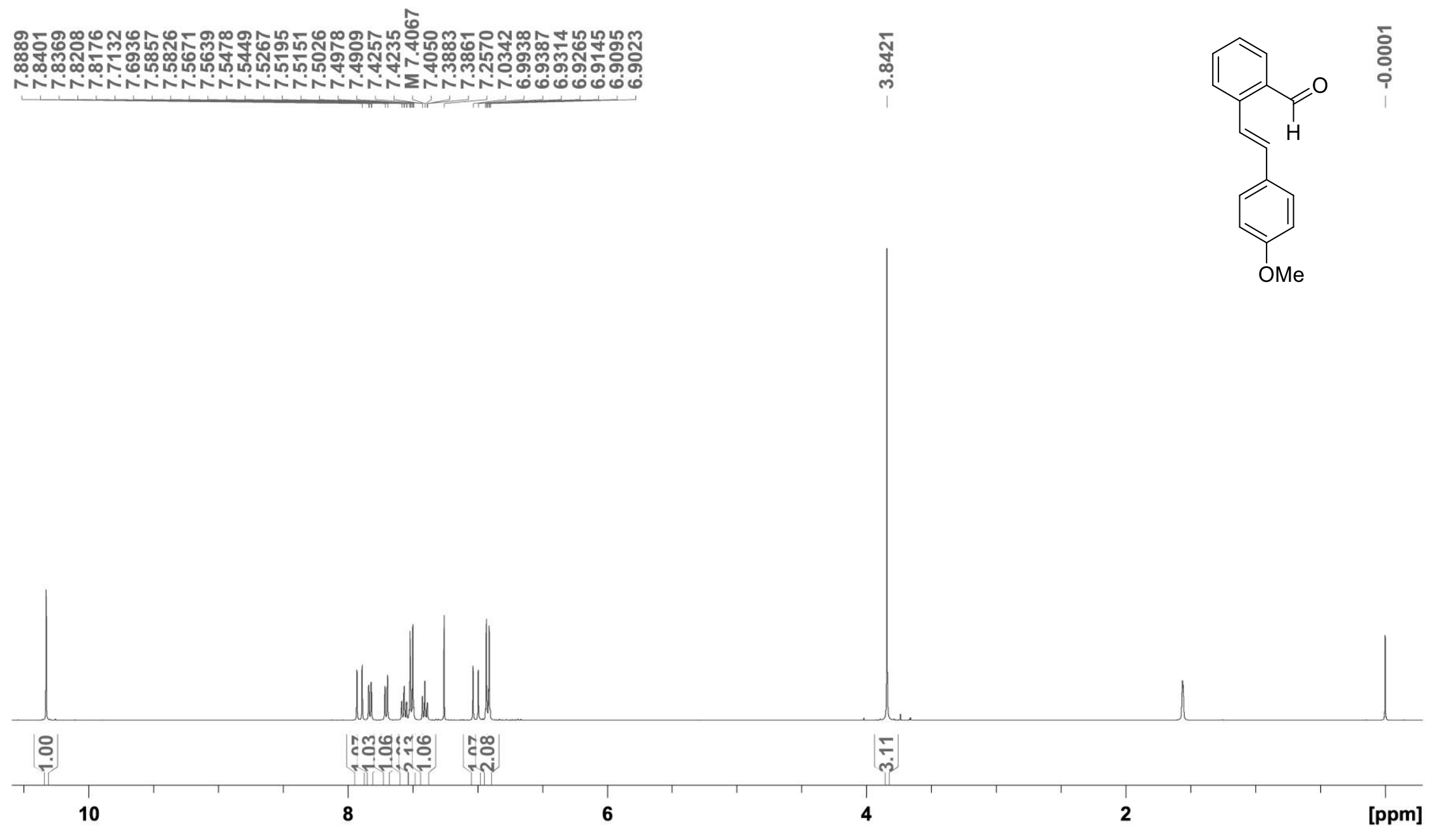

Figure S5. ${ }^{1} \mathrm{H}$ NMR $\left(\mathrm{CDCl}_{3}, 400 \mathrm{MHz}\right)$ spectrum of stilbene 3 


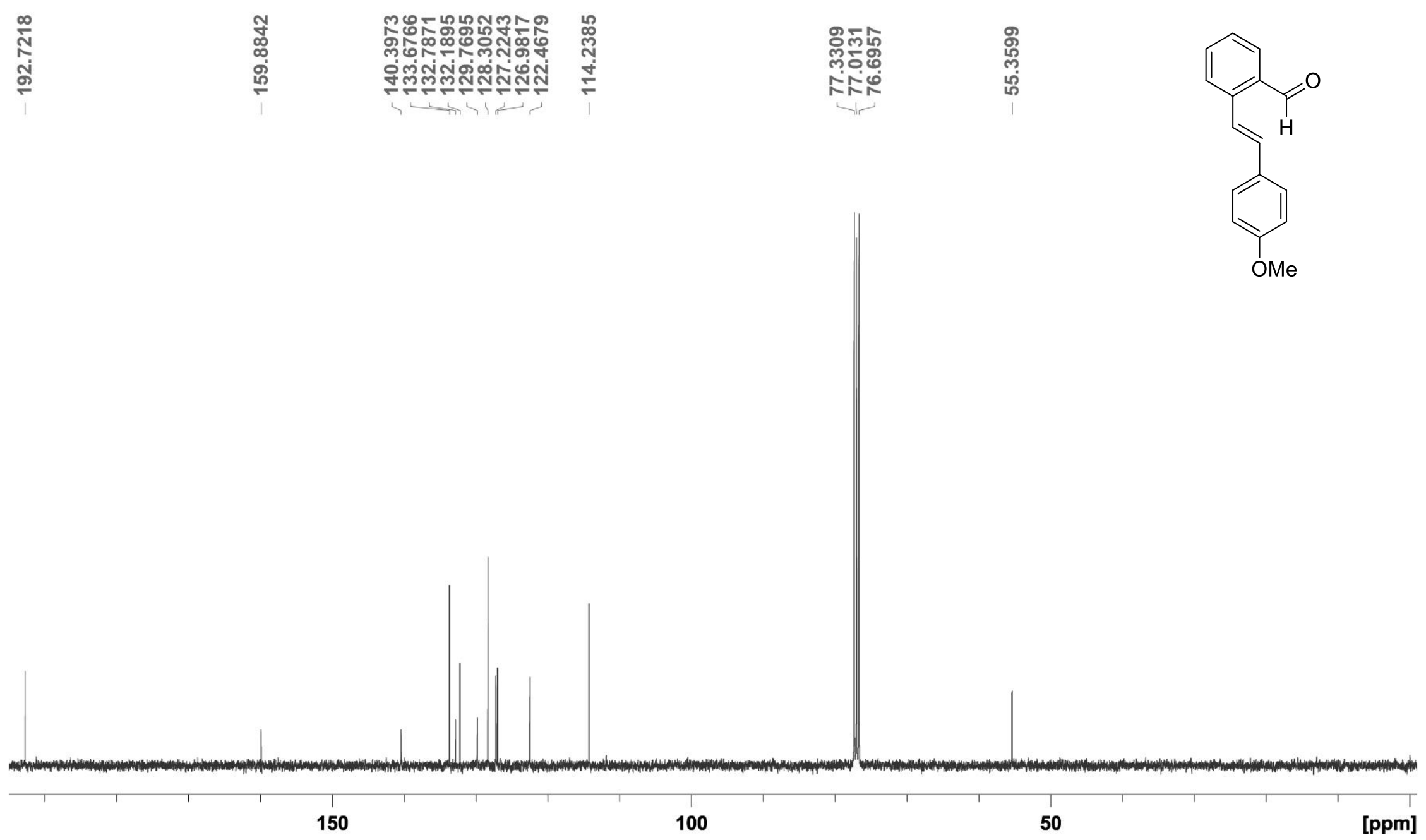

Figure S6. ${ }^{13} \mathrm{C}\left\{{ }^{1} \mathrm{H}\right\}$ NMR $\left(\mathrm{CDCl}_{3}, 100 \mathrm{MHz}\right)$ spectrum of stilbene $\mathbf{3}$ 


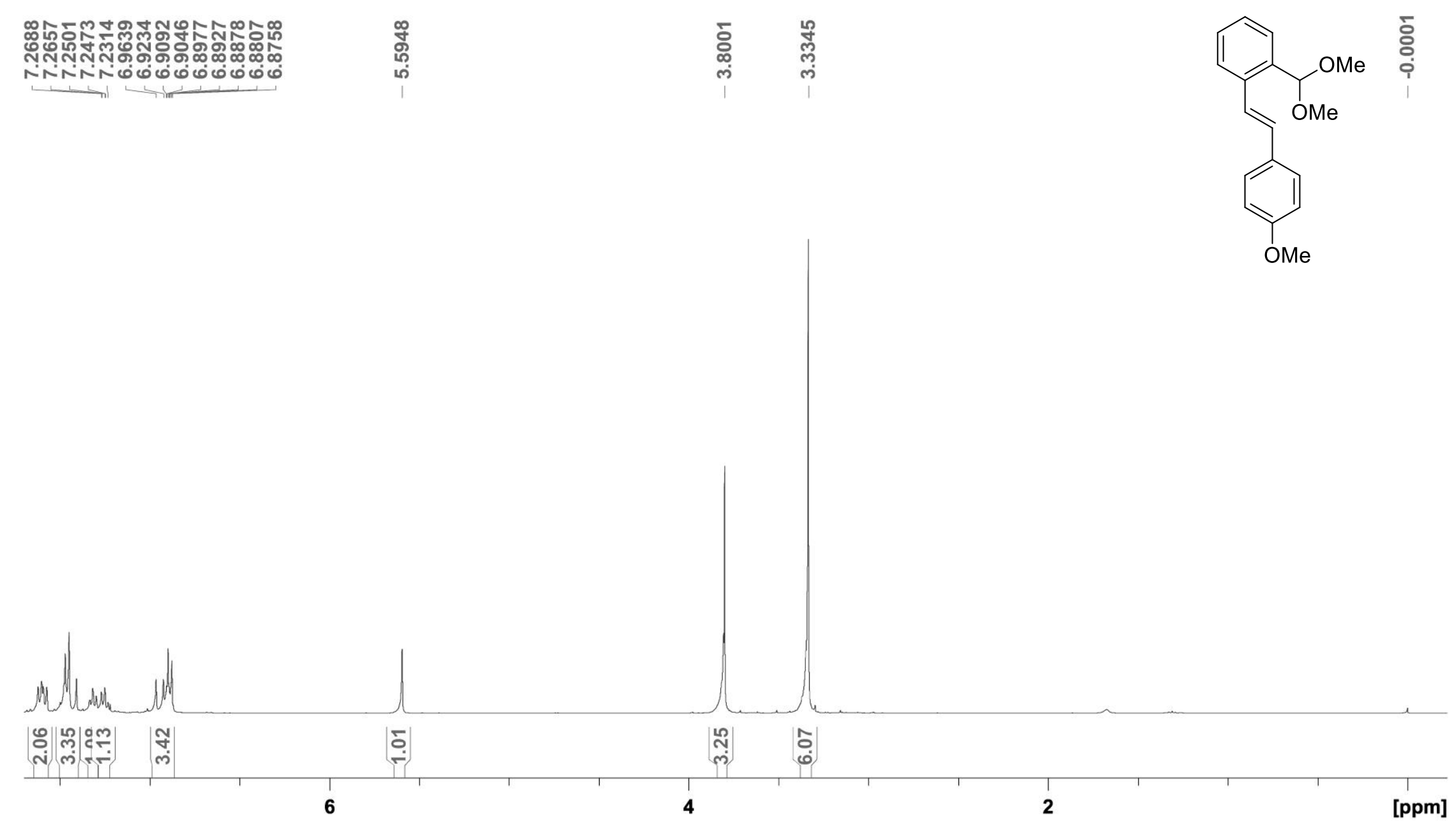

Figure S7. ${ }^{1} \mathrm{H}$ NMR $\left(\mathrm{CDCl}_{3}, 400 \mathrm{MHz}\right)$ spectrum of stilbene 4 

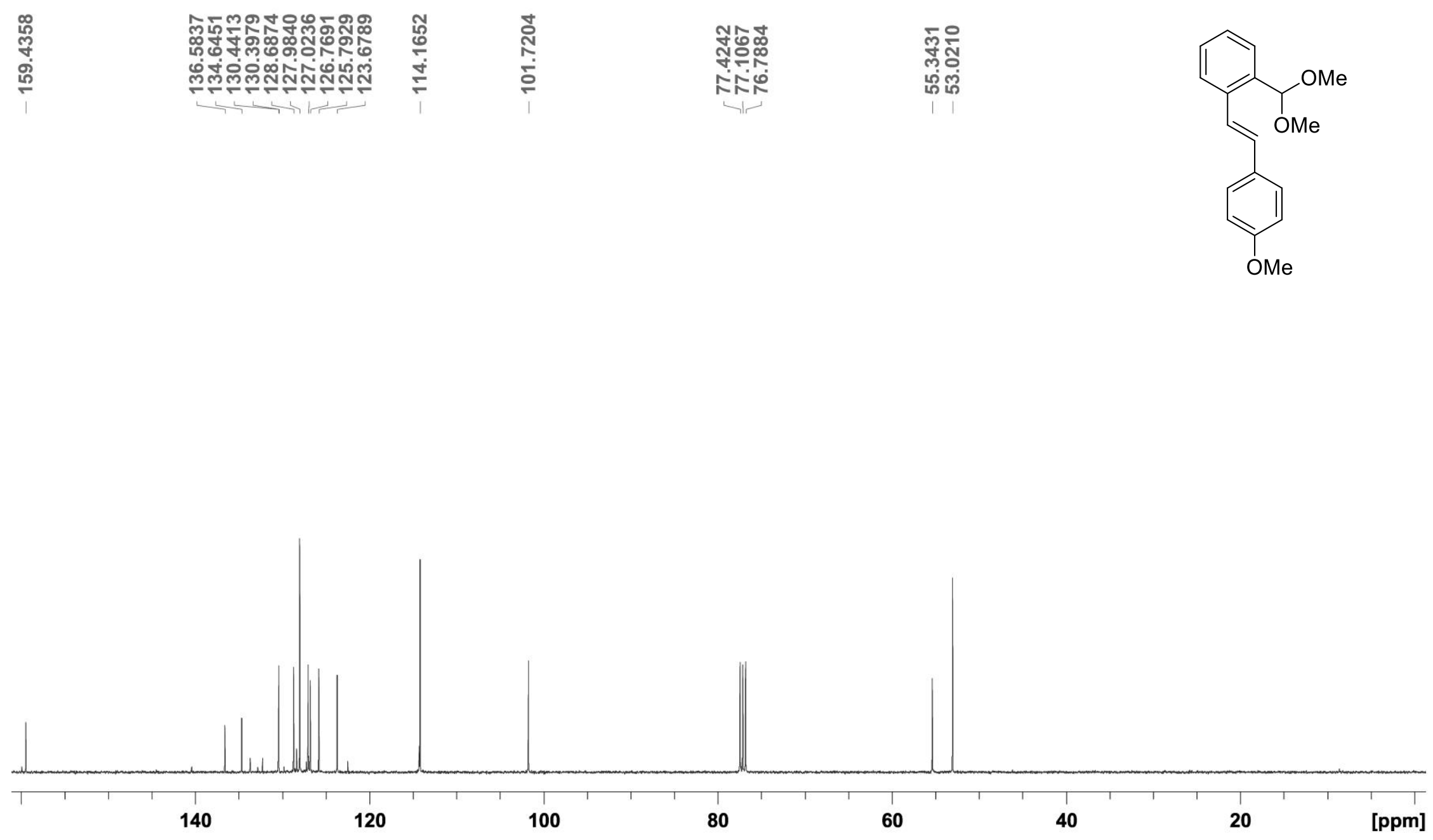

Figure S8. ${ }^{13} \mathrm{C}\left\{{ }^{1} \mathrm{H}\right\} \mathrm{NMR}\left(\mathrm{CDCl}_{3}, 100 \mathrm{MHz}\right)$ spectrum of stilbene 4 


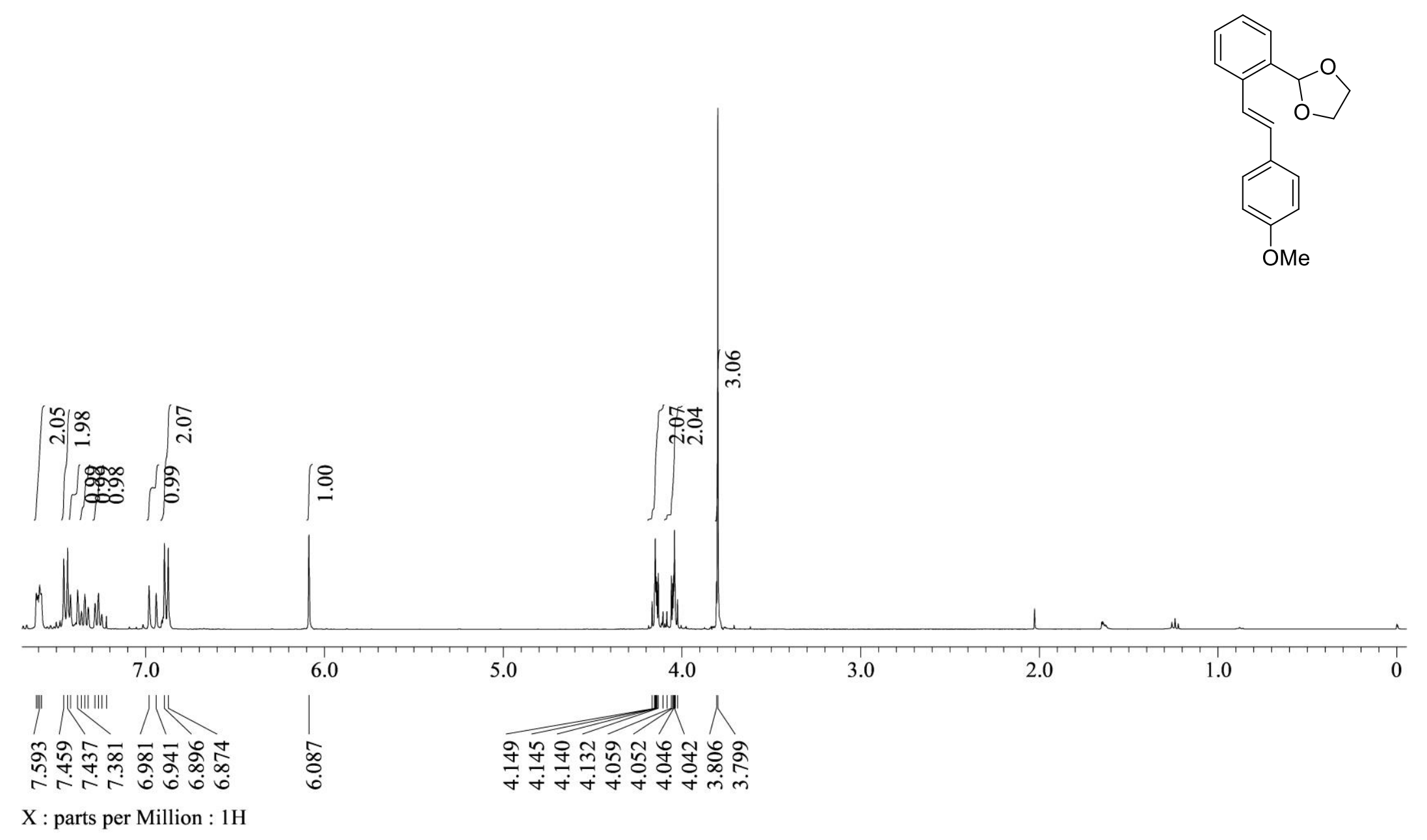

Figure S9. ${ }^{1} \mathrm{H} \mathrm{NMR}\left(\mathrm{CDCl}_{3}, 400 \mathrm{MHz}\right)$ spectrum of stilbene 5 

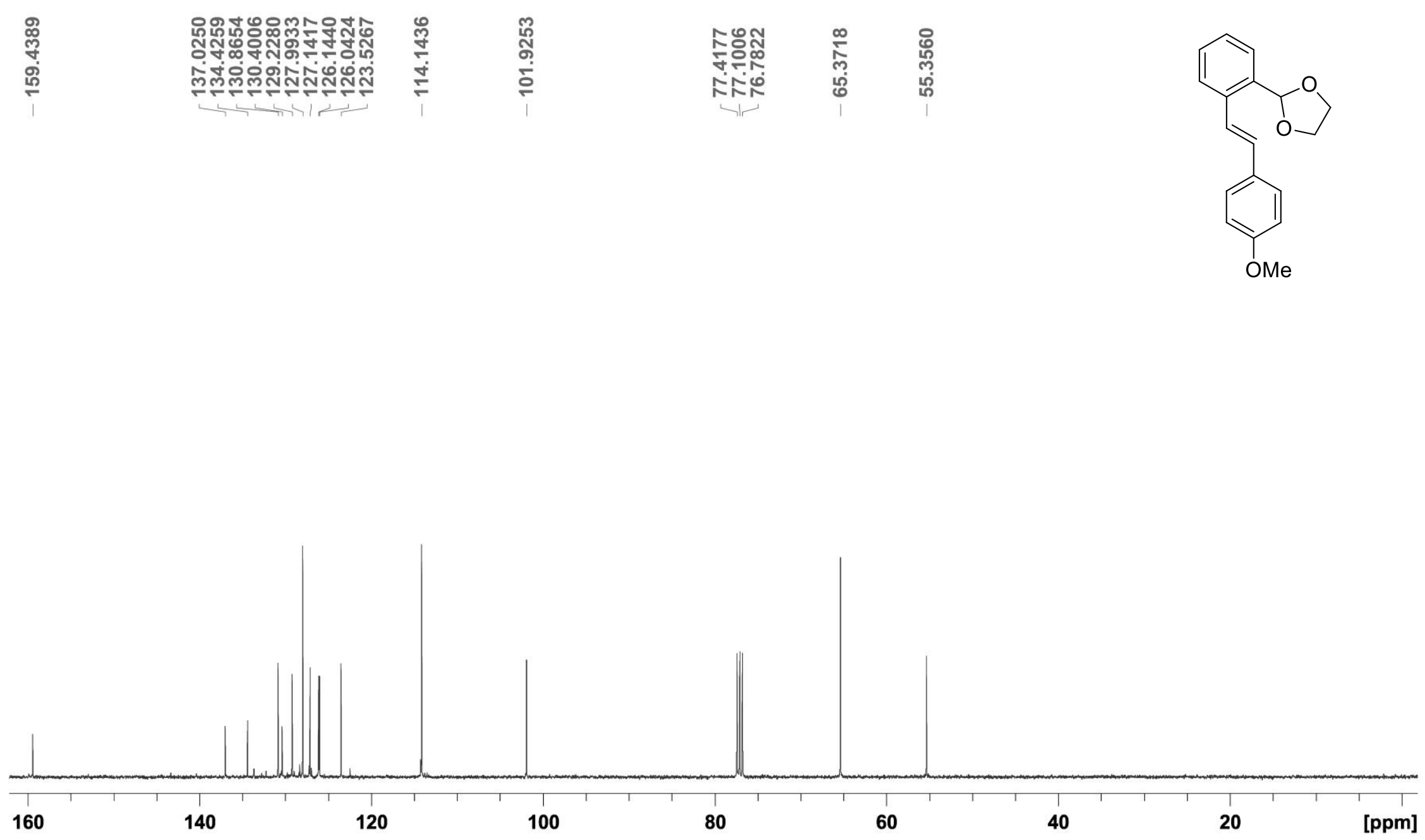

Figure $\mathrm{S} 10 .{ }^{13} \mathrm{C}\left\{{ }^{1} \mathrm{H}\right\} \mathrm{NMR}\left(\mathrm{CDCl}_{3}, 100 \mathrm{MHz}\right)$ spectrum of stilbene 5 


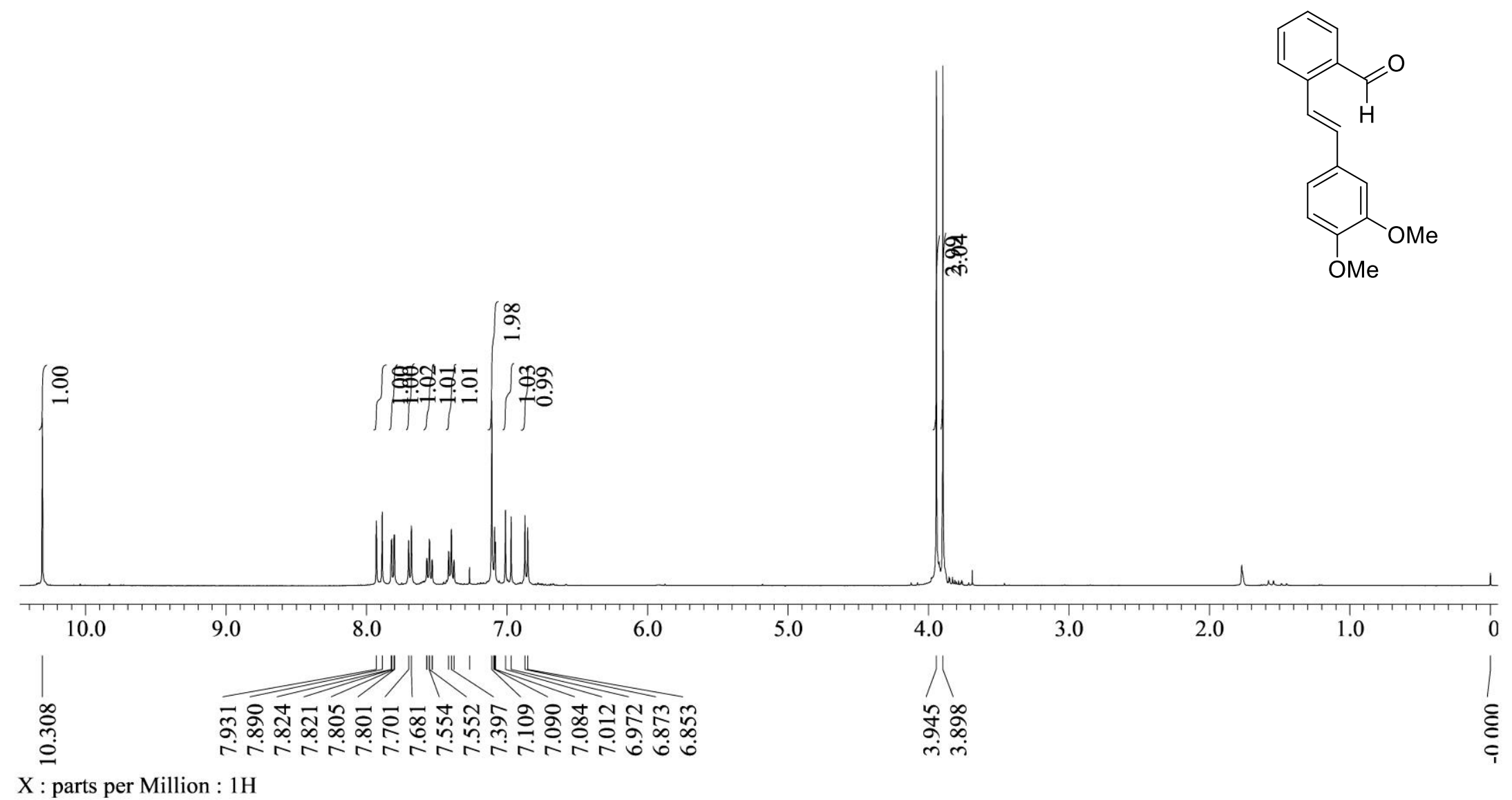

Figure S11. ${ }^{1} \mathrm{H} \mathrm{NMR}\left(\mathrm{CDCl}_{3}, 400 \mathrm{MHz}\right)$ spectrum of stilbene 6 


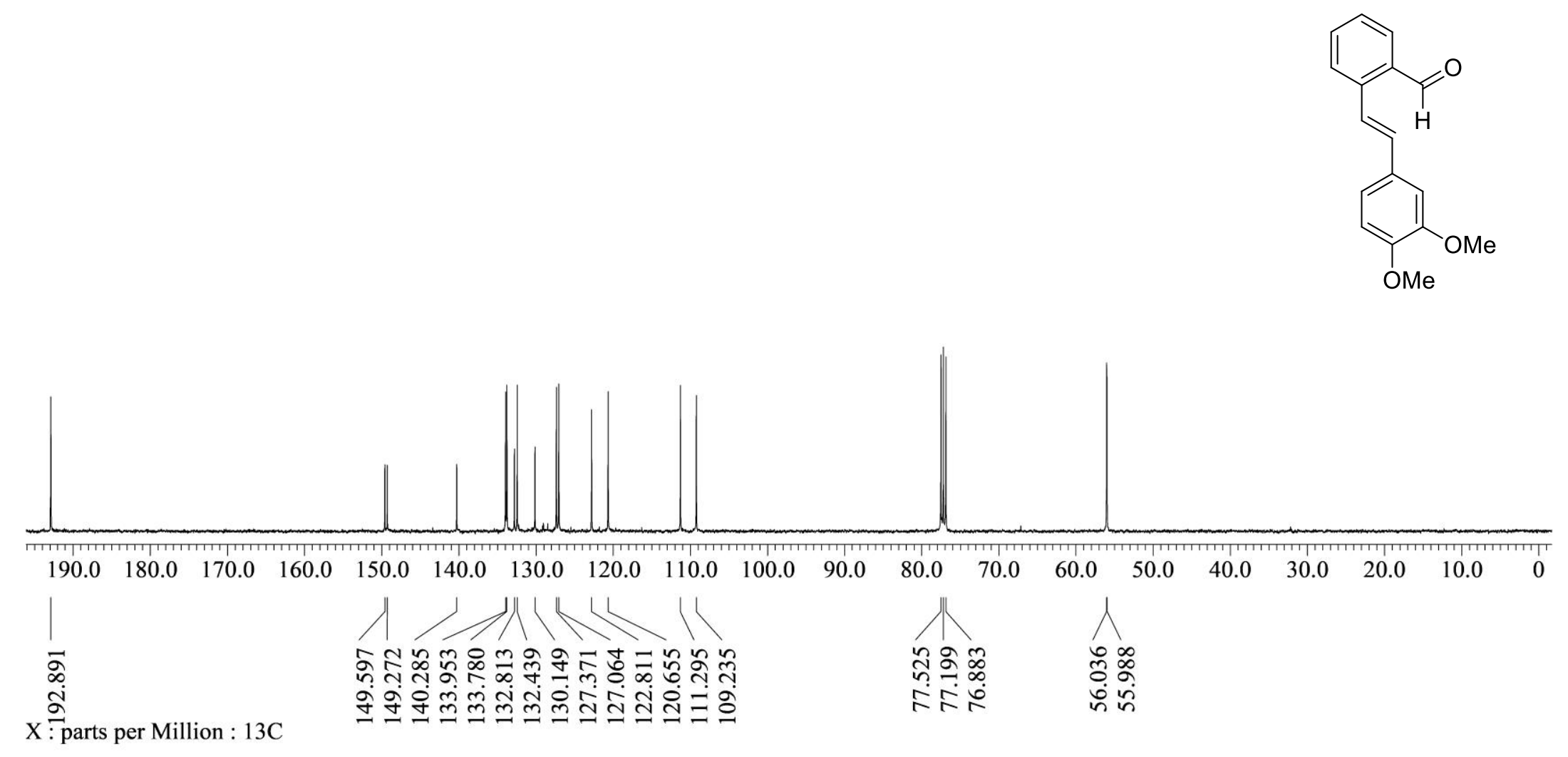

Figure $\mathrm{S} 12 .{ }^{13} \mathrm{C}\left\{{ }^{1} \mathrm{H}\right\}$ NMR $\left(\mathrm{CDCl}_{3}, 100 \mathrm{MHz}\right)$ spectrum of stilbene $\mathbf{6}$ 


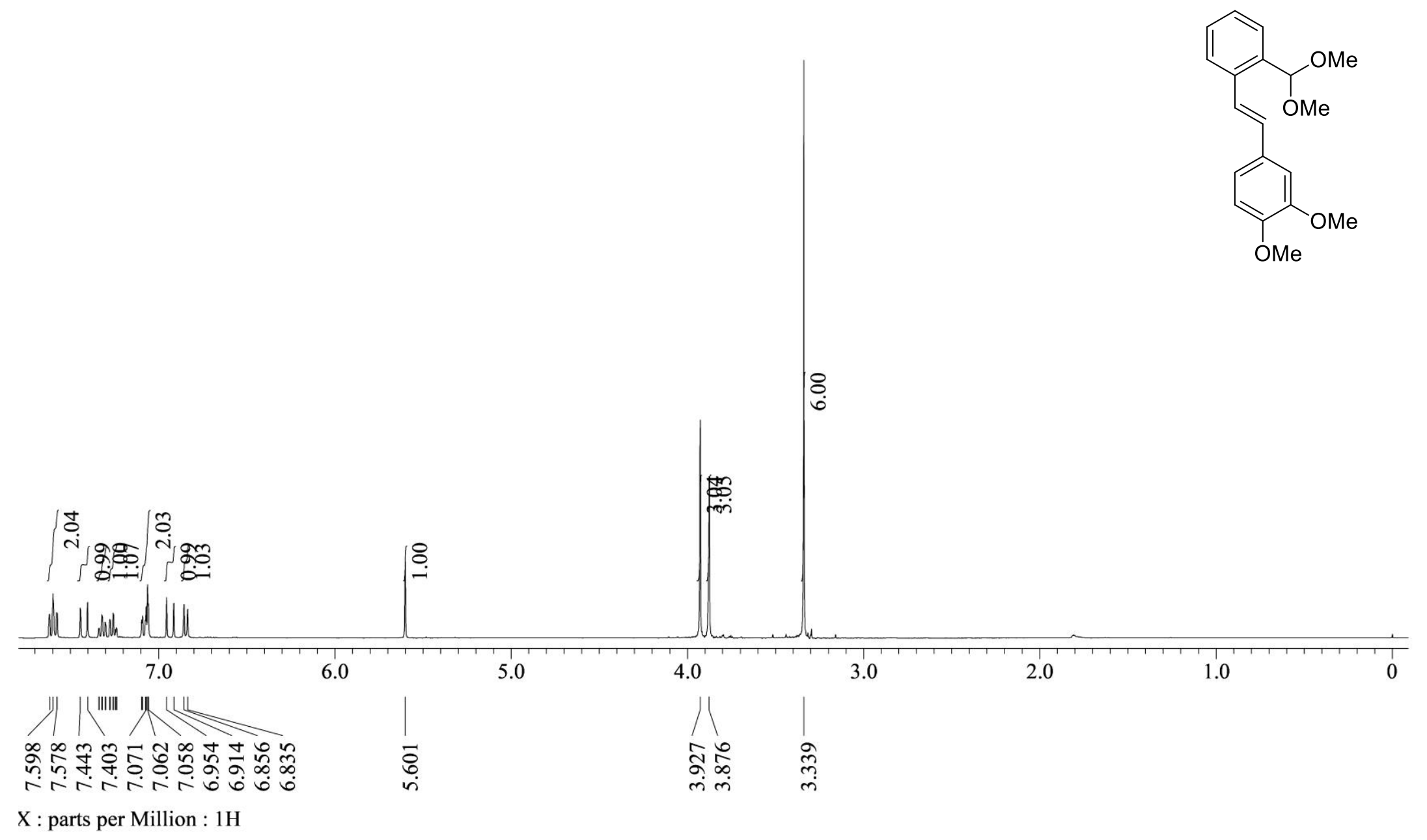

Figure S13. ${ }^{1} \mathrm{H}$ NMR $\left(\mathrm{CDCl}_{3}, 400 \mathrm{MHz}\right)$ spectrum of stilbene 7 

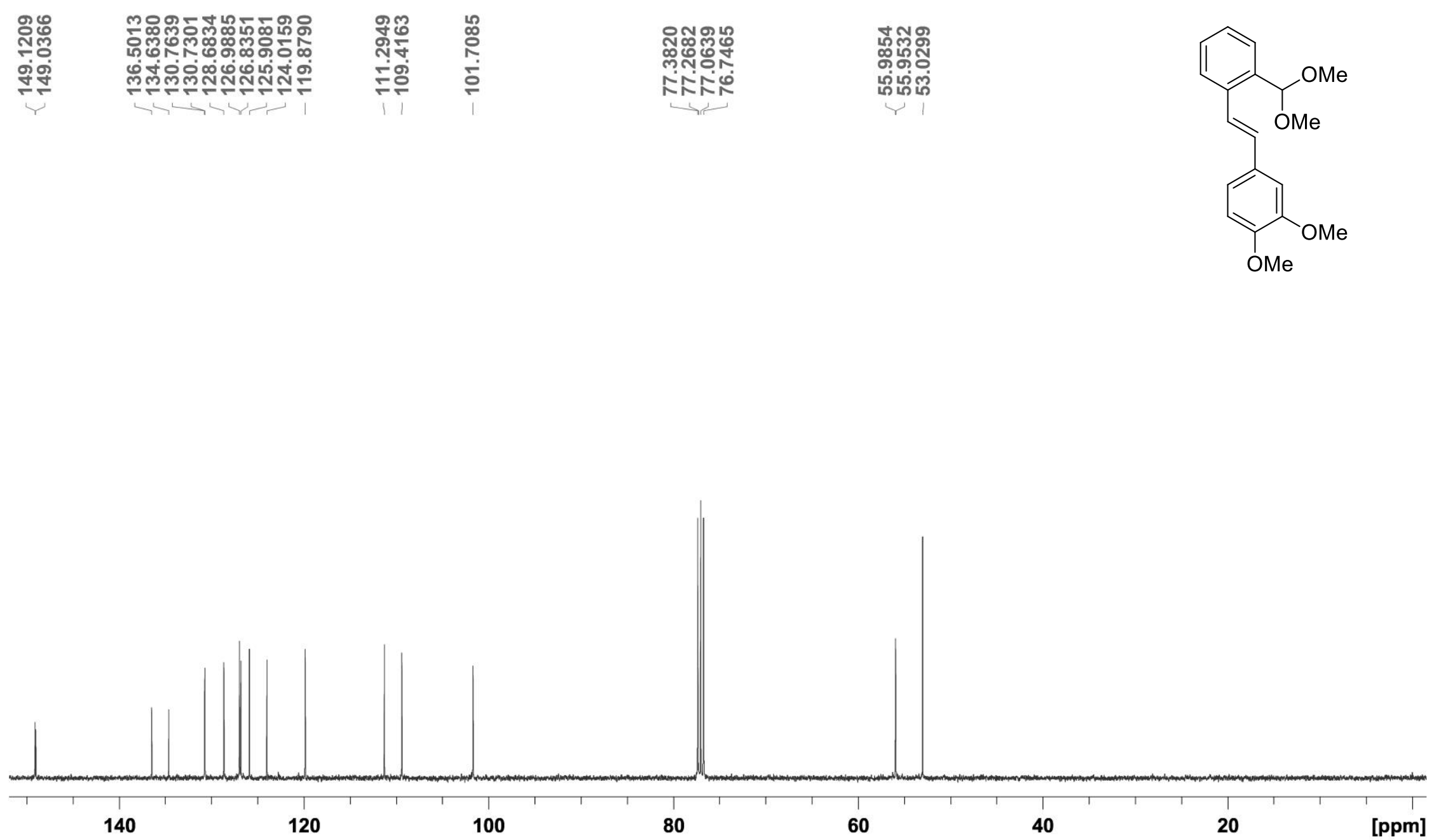

Figure $\mathrm{S} 14 .{ }^{13} \mathrm{C}\left\{{ }^{1} \mathrm{H}\right\}$ NMR $\left(\mathrm{CDCl}_{3}, 100 \mathrm{MHz}\right)$ spectrum of stilbene 7 


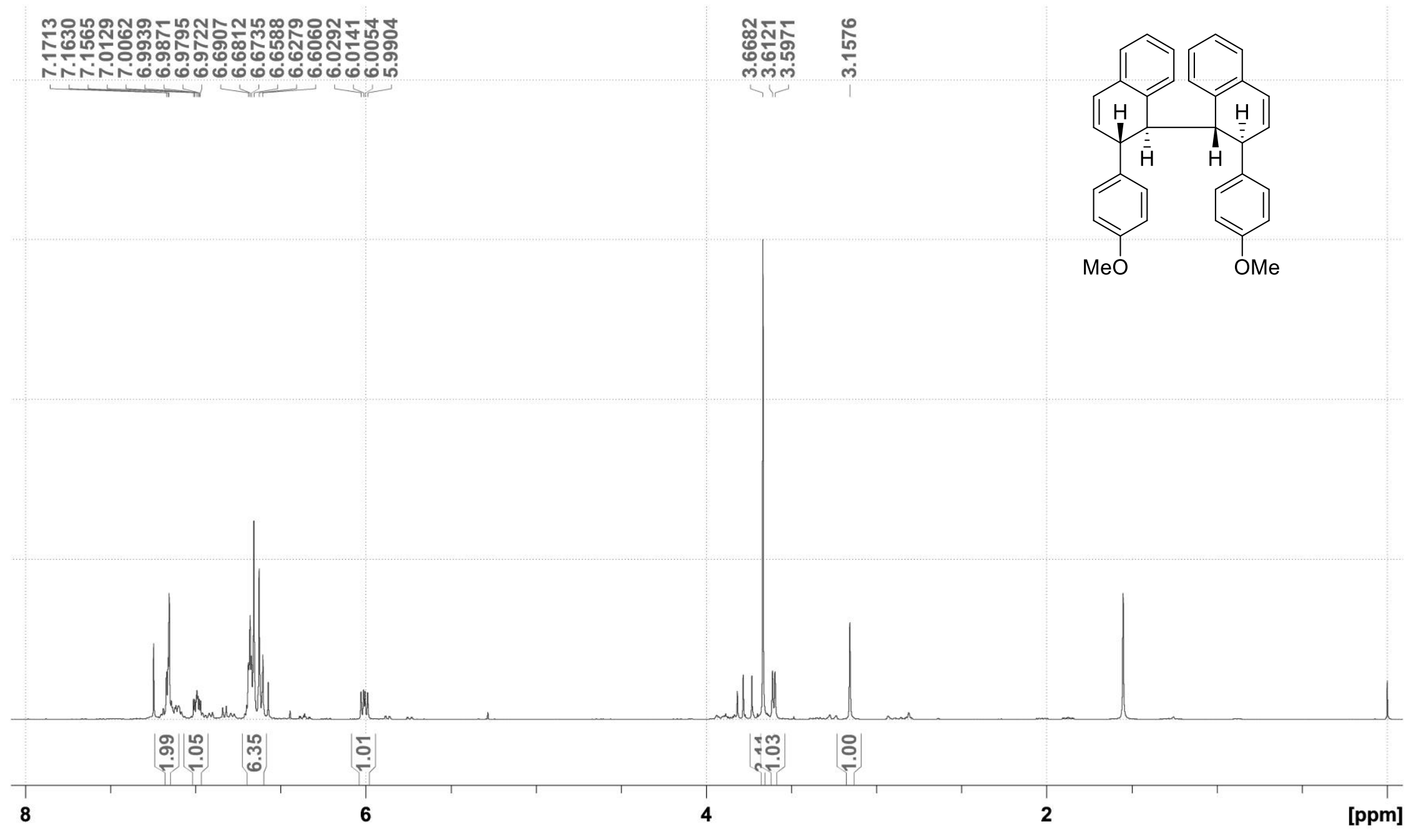

Figure S15. ${ }^{1} \mathrm{H} \mathrm{NMR}\left(\mathrm{CDCl}_{3}, 400 \mathrm{MHz}\right)$ spectrum of compound 1a 


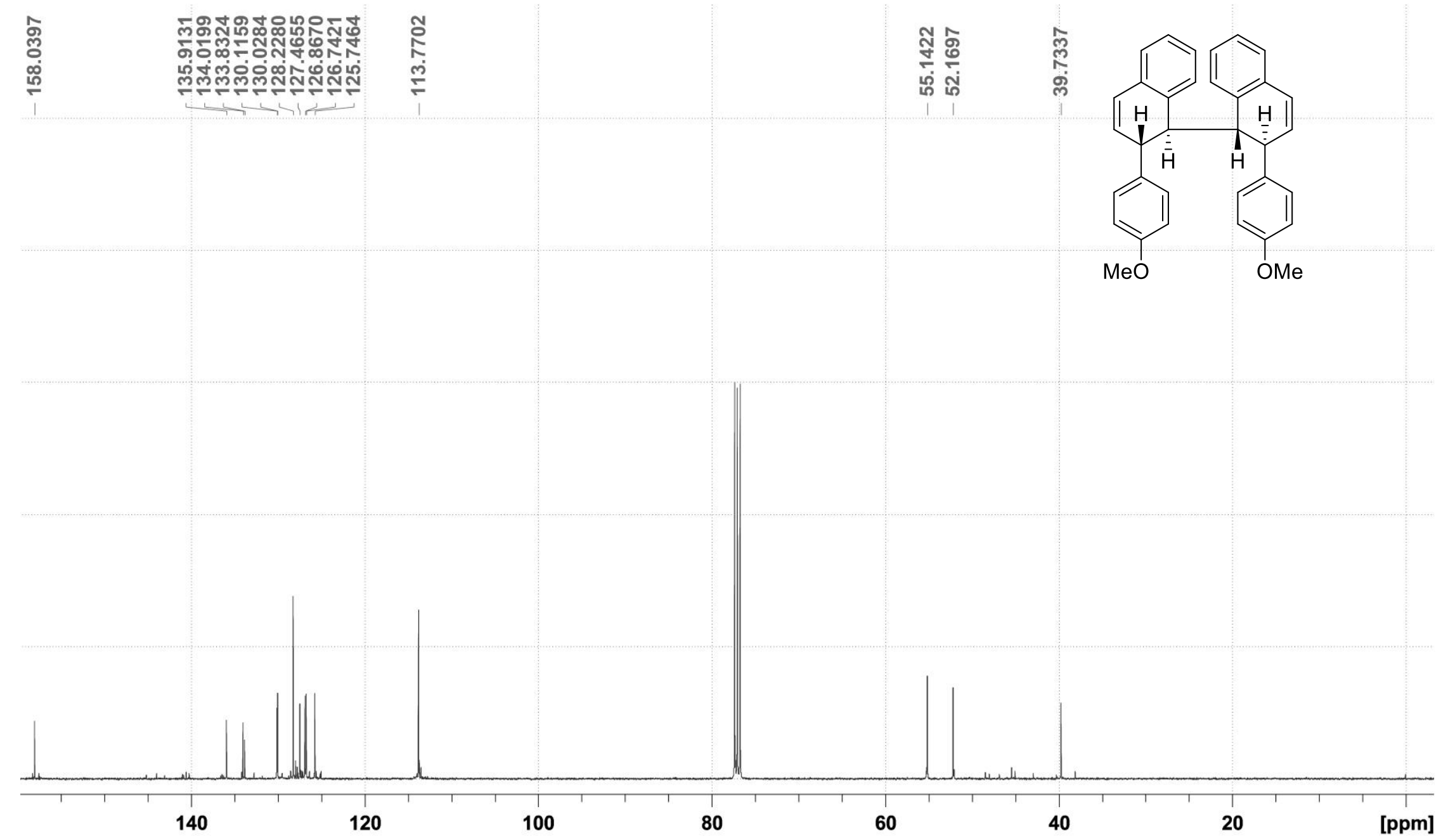

Figure $\mathrm{S} 16 .{ }^{13} \mathrm{C}\left\{{ }^{1} \mathrm{H}\right\} \mathrm{NMR}\left(\mathrm{CDCl}_{3}, 100 \mathrm{MHz}\right)$ spectrum of compound 1a 


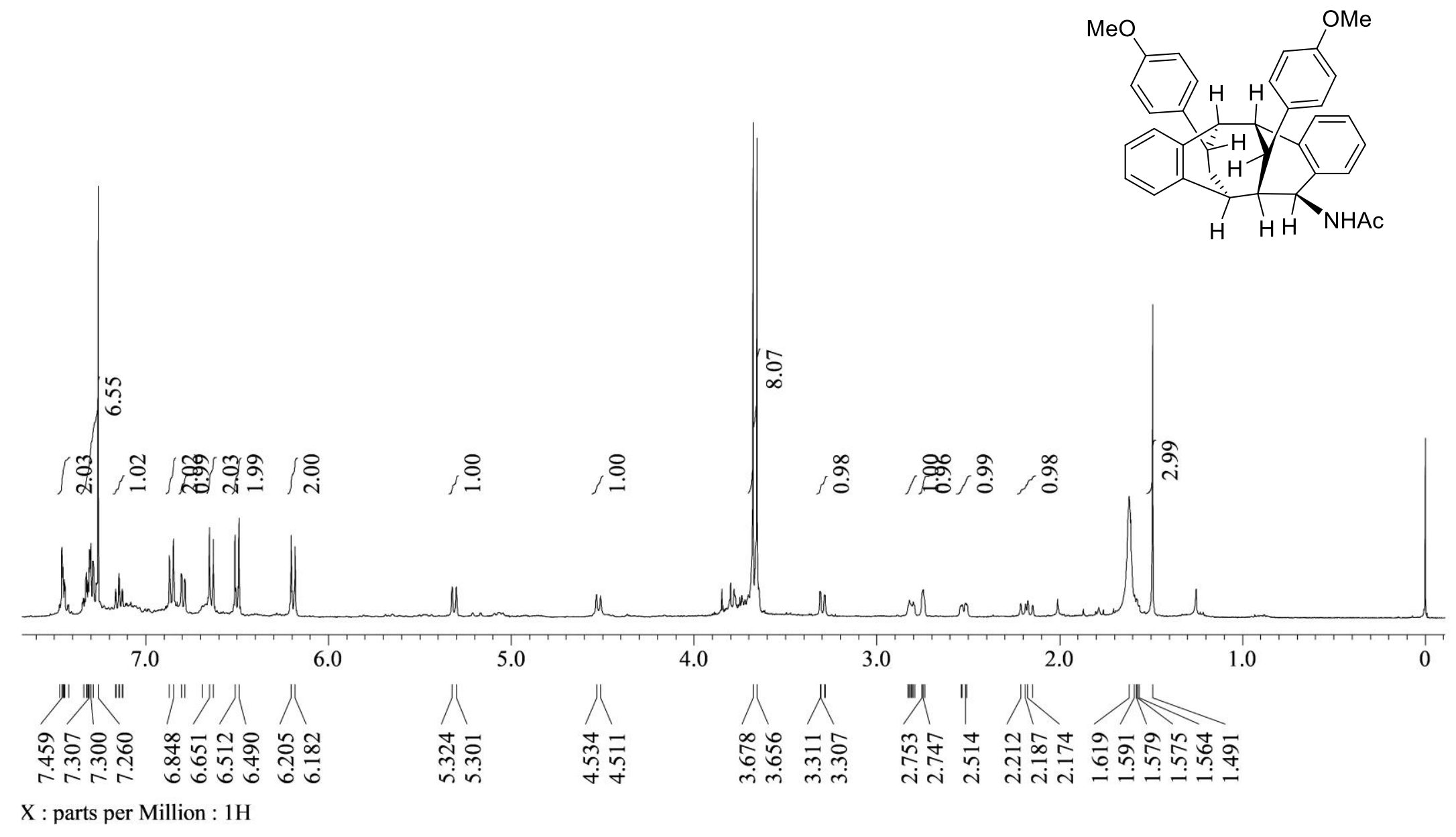

Figure S17. ${ }^{1} \mathrm{H} \mathrm{NMR}\left(\mathrm{CDCl}_{3}, 400 \mathrm{MHz}\right)$ spectrum of compound $\mathbf{1 b}$ 


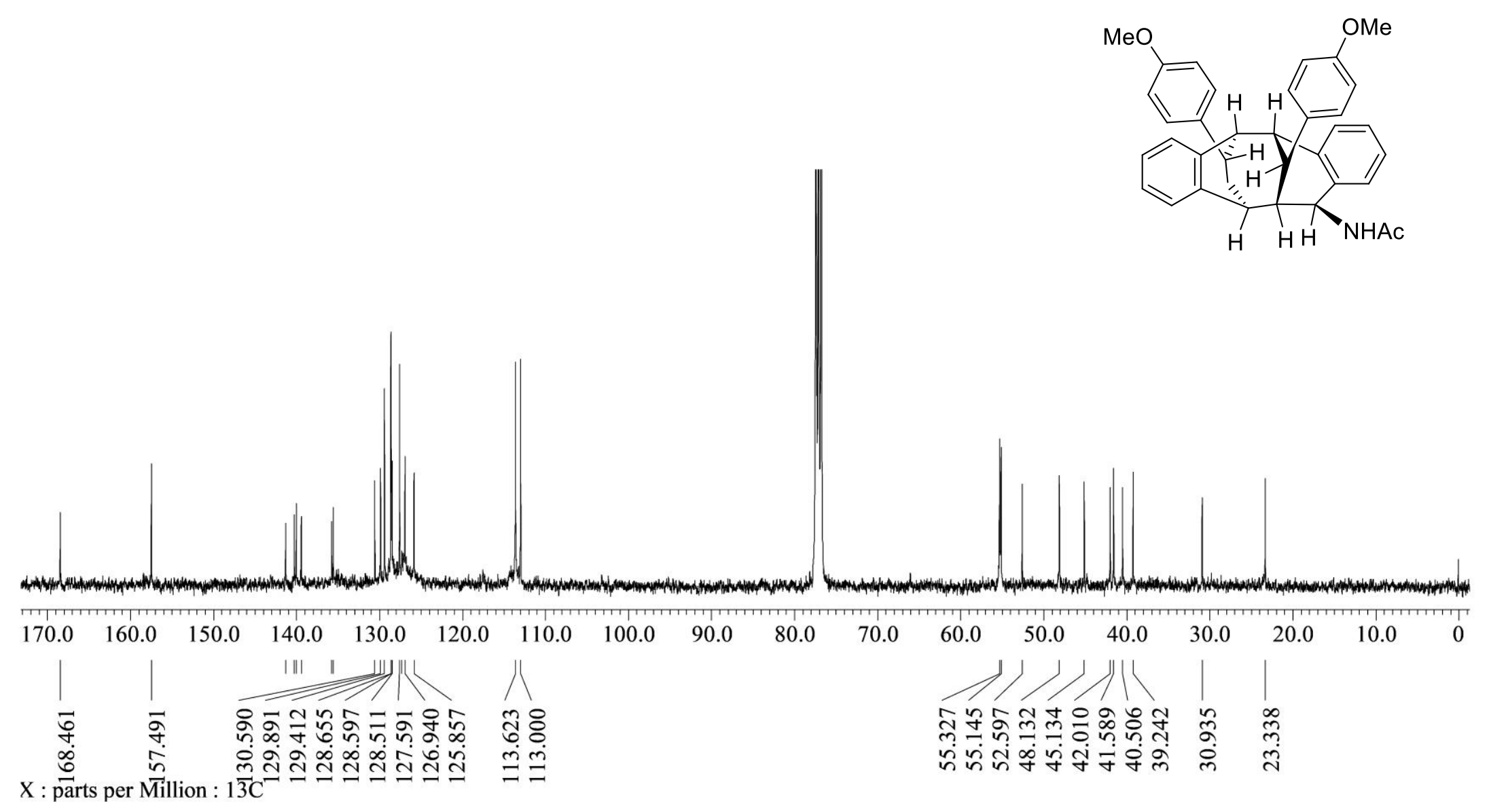

Figure S18. ${ }^{13} \mathrm{C}\left\{{ }^{1} \mathrm{H}\right\}$ NMR $\left(\mathrm{CDCl}_{3}, 100 \mathrm{MHz}\right)$ spectrum of compound $\mathbf{1 b}$ 


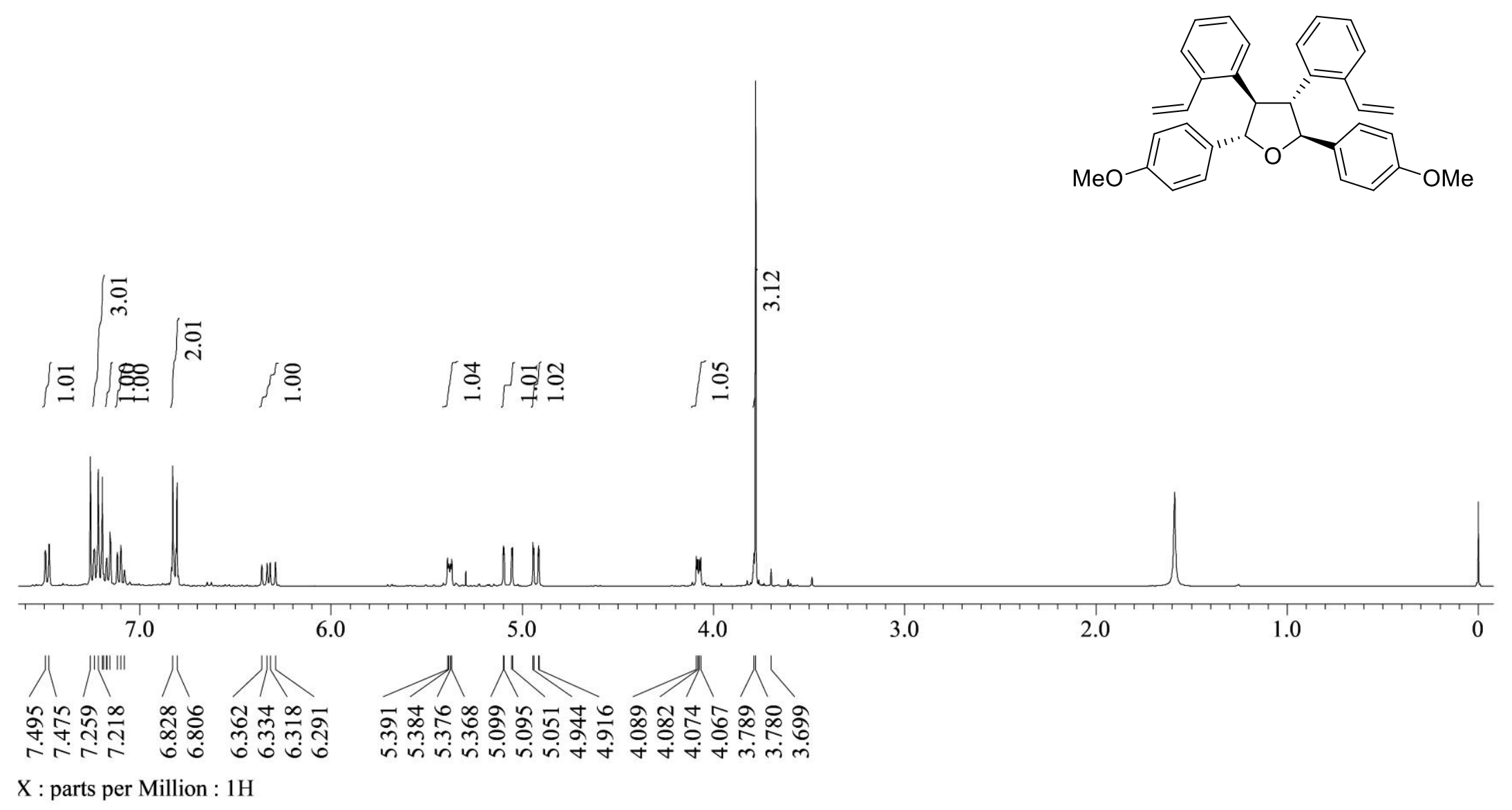

Figure S19. ${ }^{1} \mathrm{H} \mathrm{NMR}\left(\mathrm{CDCl}_{3}, 400 \mathrm{MHz}\right)$ spectrum of compound 1c 


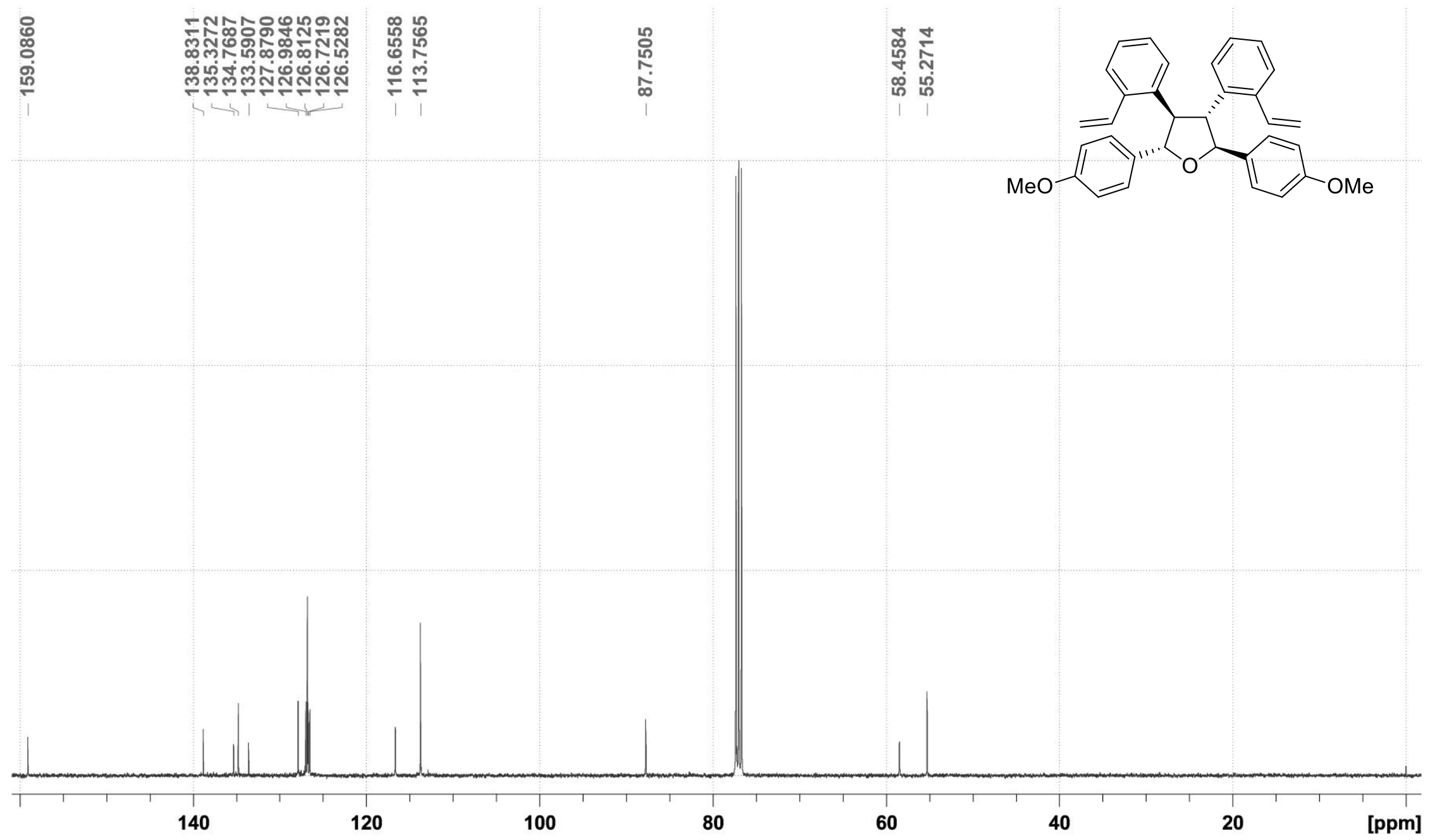

Figure $\mathrm{S} 20 .{ }^{13} \mathrm{C}\left\{{ }^{1} \mathrm{H}\right\} \mathrm{NMR}\left(\mathrm{CDCl}_{3}, 100 \mathrm{MHz}\right)$ spectrum of compound 1c 


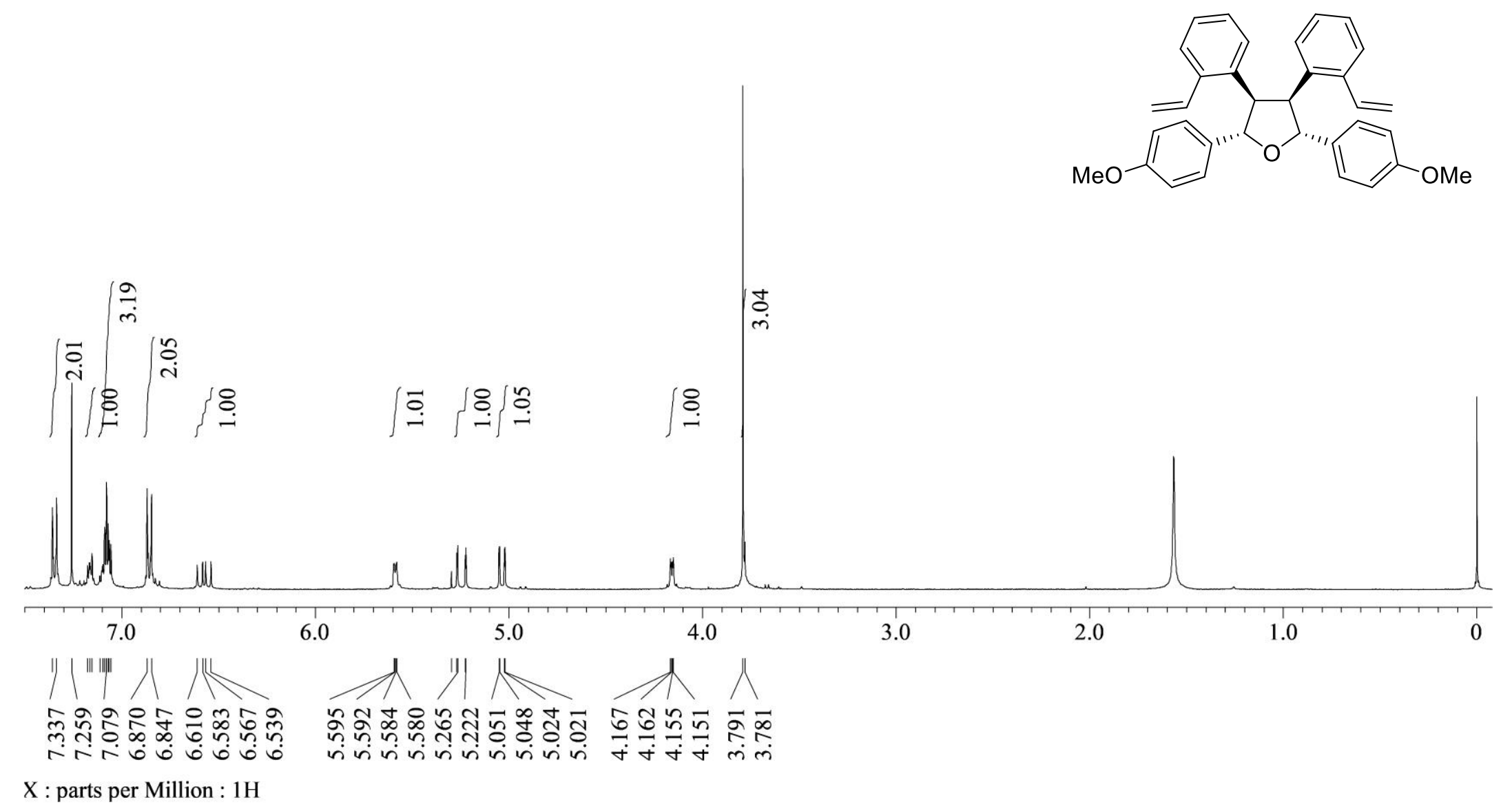

Figure S21. ${ }^{1} \mathrm{H} \mathrm{NMR}\left(\mathrm{CDCl}_{3}, 400 \mathrm{MHz}\right)$ spectrum of compound 1d 


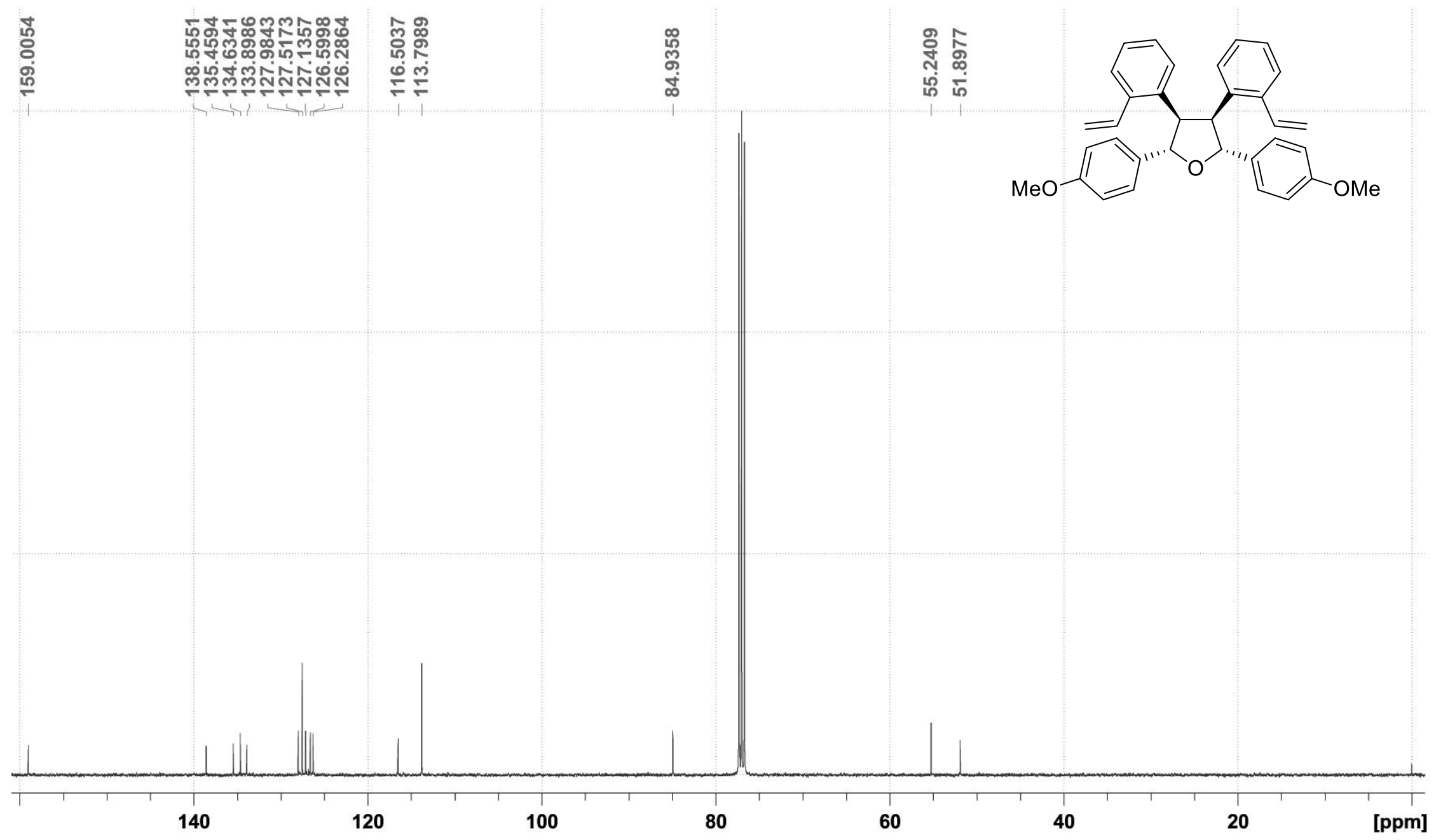

Figure $\mathrm{S} 22 .{ }^{13} \mathrm{C}\left\{{ }^{1} \mathrm{H}\right\} \mathrm{NMR}\left(\mathrm{CDCl}_{3}, 100 \mathrm{MHz}\right)$ spectrum of compound 1d 


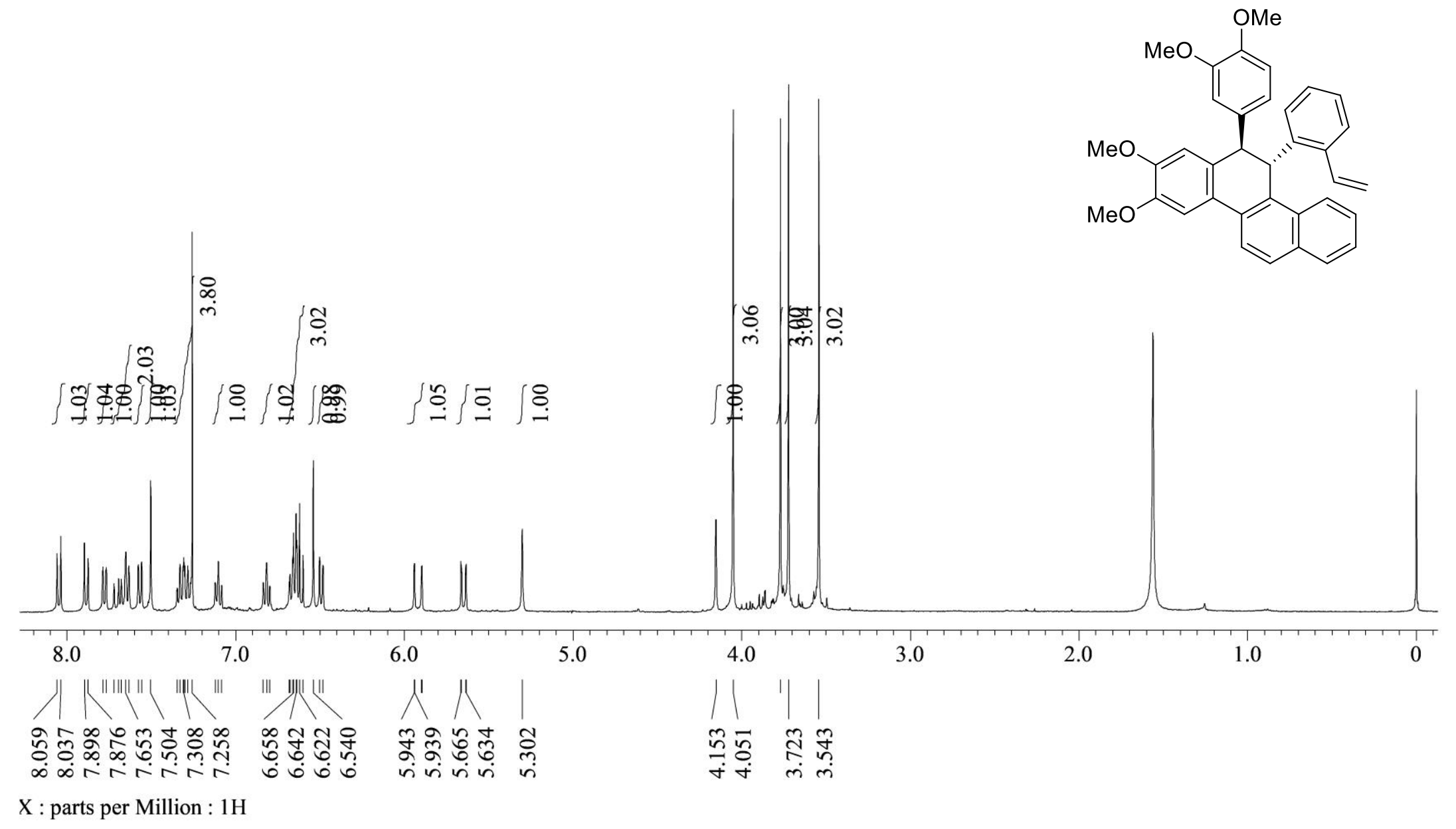

Figure S23. ${ }^{1} \mathrm{H} \mathrm{NMR}\left(\mathrm{CDCl}_{3}, 400 \mathrm{MHz}\right)$ spectrum of compound $2 \mathbf{a}$ 


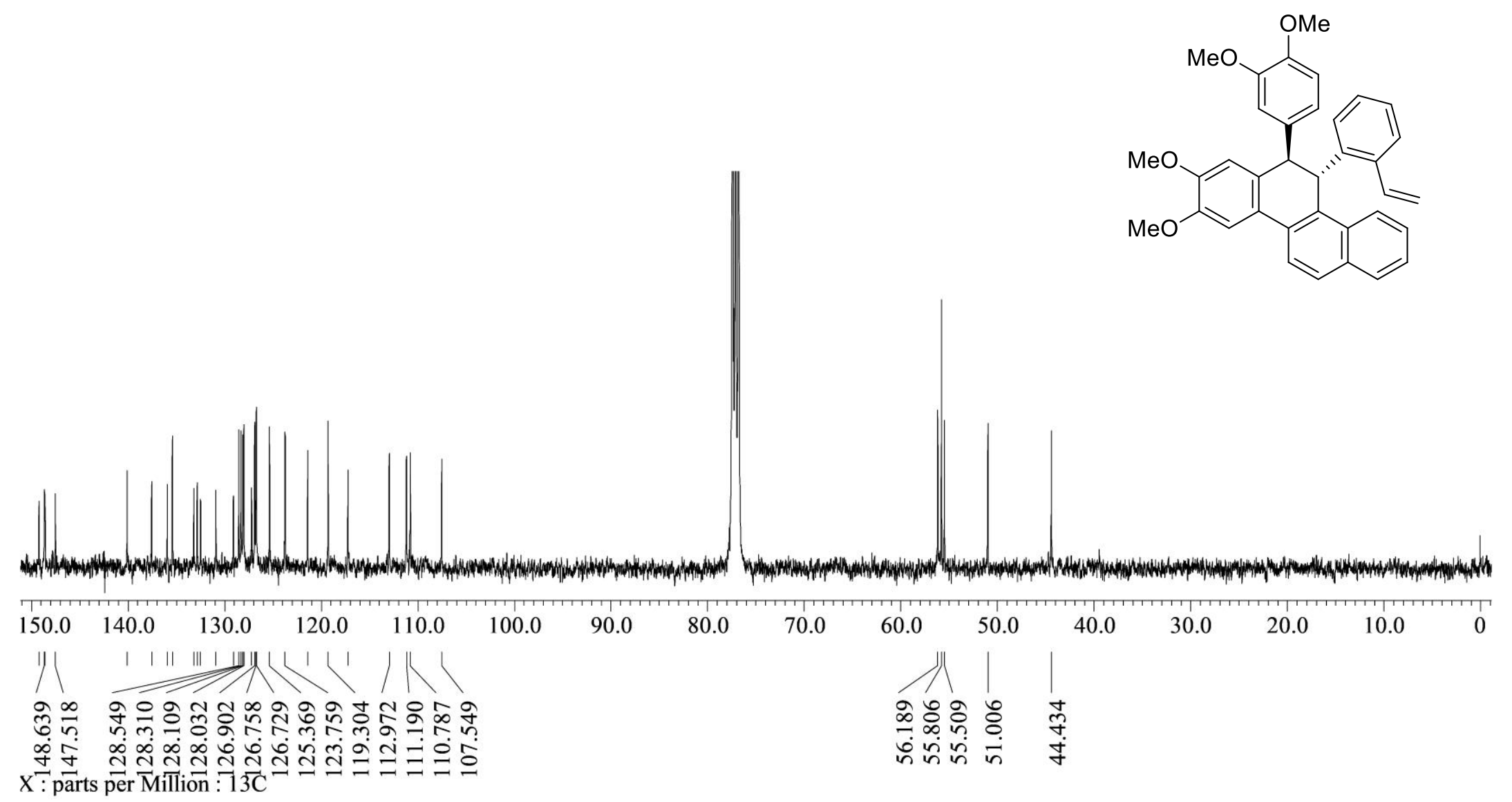

Figure S24. ${ }^{13} \mathrm{C}\left\{{ }^{1} \mathrm{H}\right\} \mathrm{NMR}\left(\mathrm{CDCl}_{3}, 100 \mathrm{MHz}\right)$ spectrum of compound 2a 


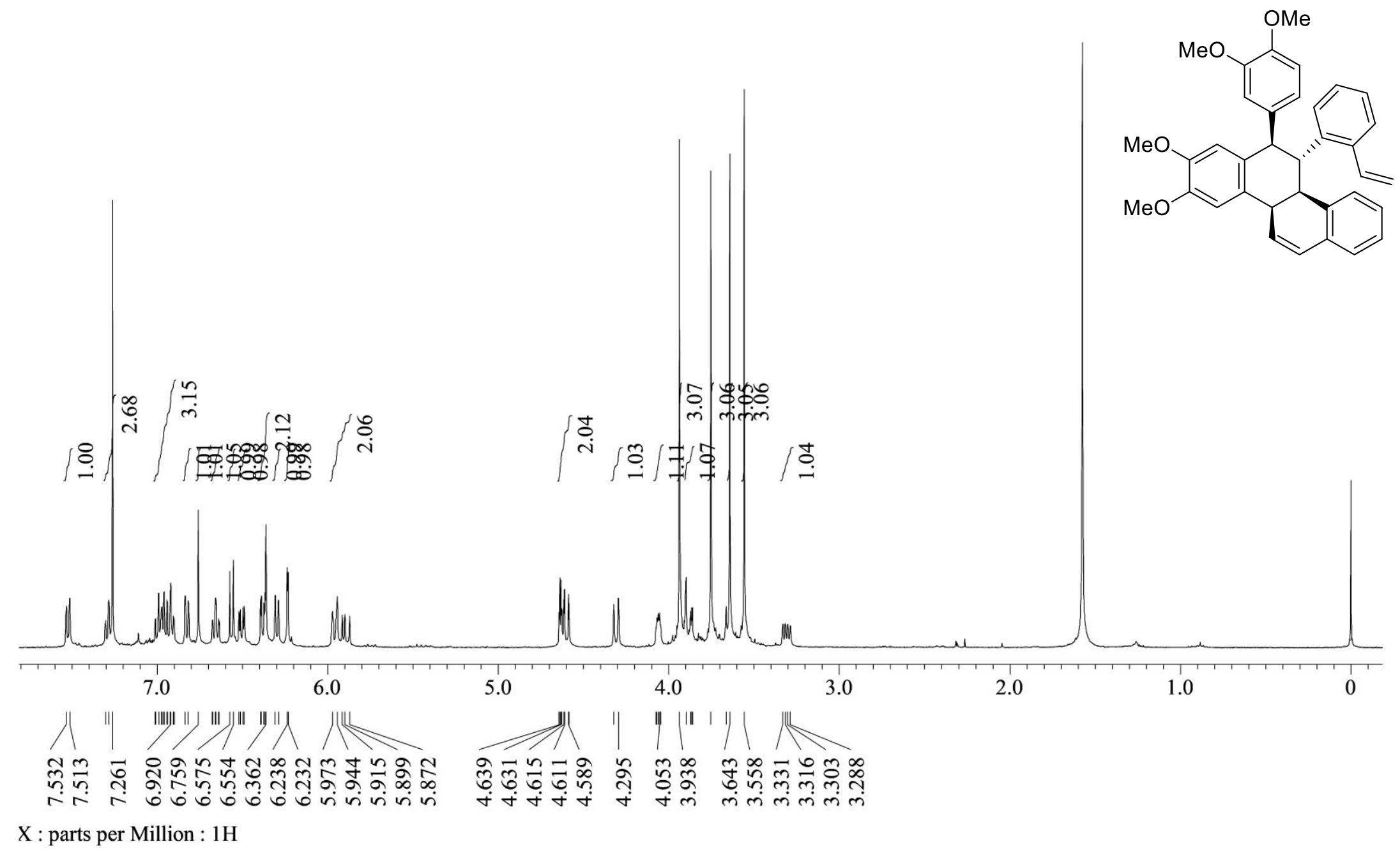

Figure S25. ${ }^{1} \mathrm{H} \mathrm{NMR}\left(\mathrm{CDCl}_{3}, 400 \mathrm{MHz}\right)$ spectrum of compound $\mathbf{2 b}$ 


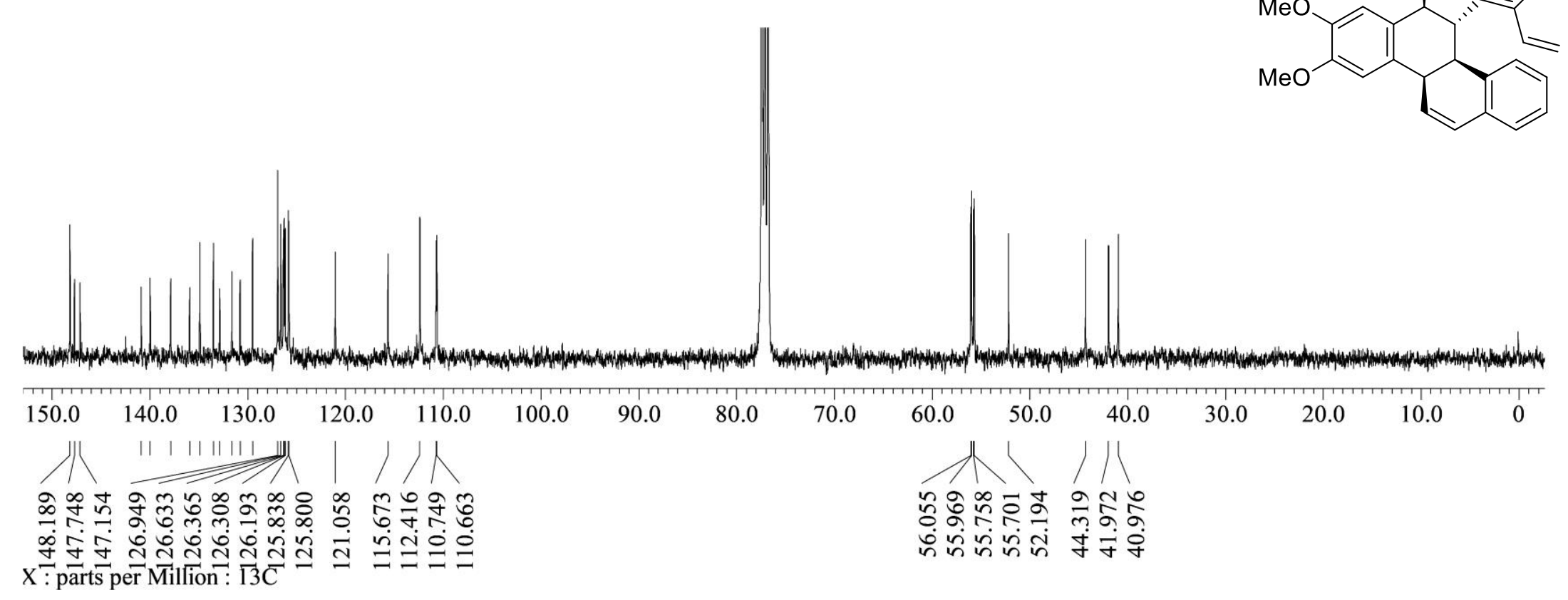

Figure S26. ${ }^{13} \mathrm{C}\left\{{ }^{1} \mathrm{H}\right\} \mathrm{NMR}\left(\mathrm{CDCl}_{3}, 100 \mathrm{MHz}\right)$ spectrum of compound $\mathbf{2 b}$ 


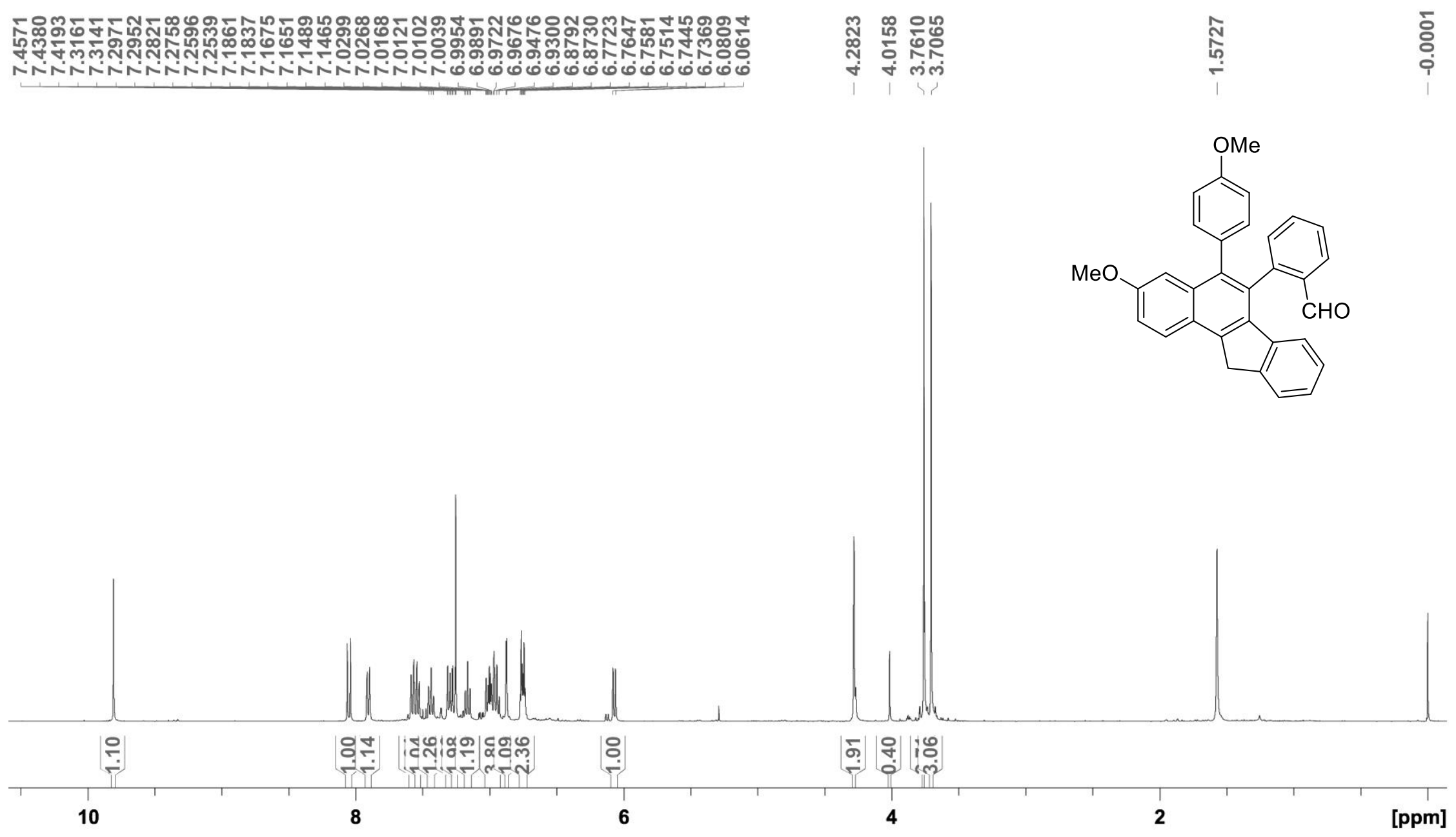

Figure S27. ${ }^{1} \mathrm{H}$ NMR $\left(\mathrm{CDCl}_{3}, 400 \mathrm{MHz}\right)$ spectrum of compound 3a 


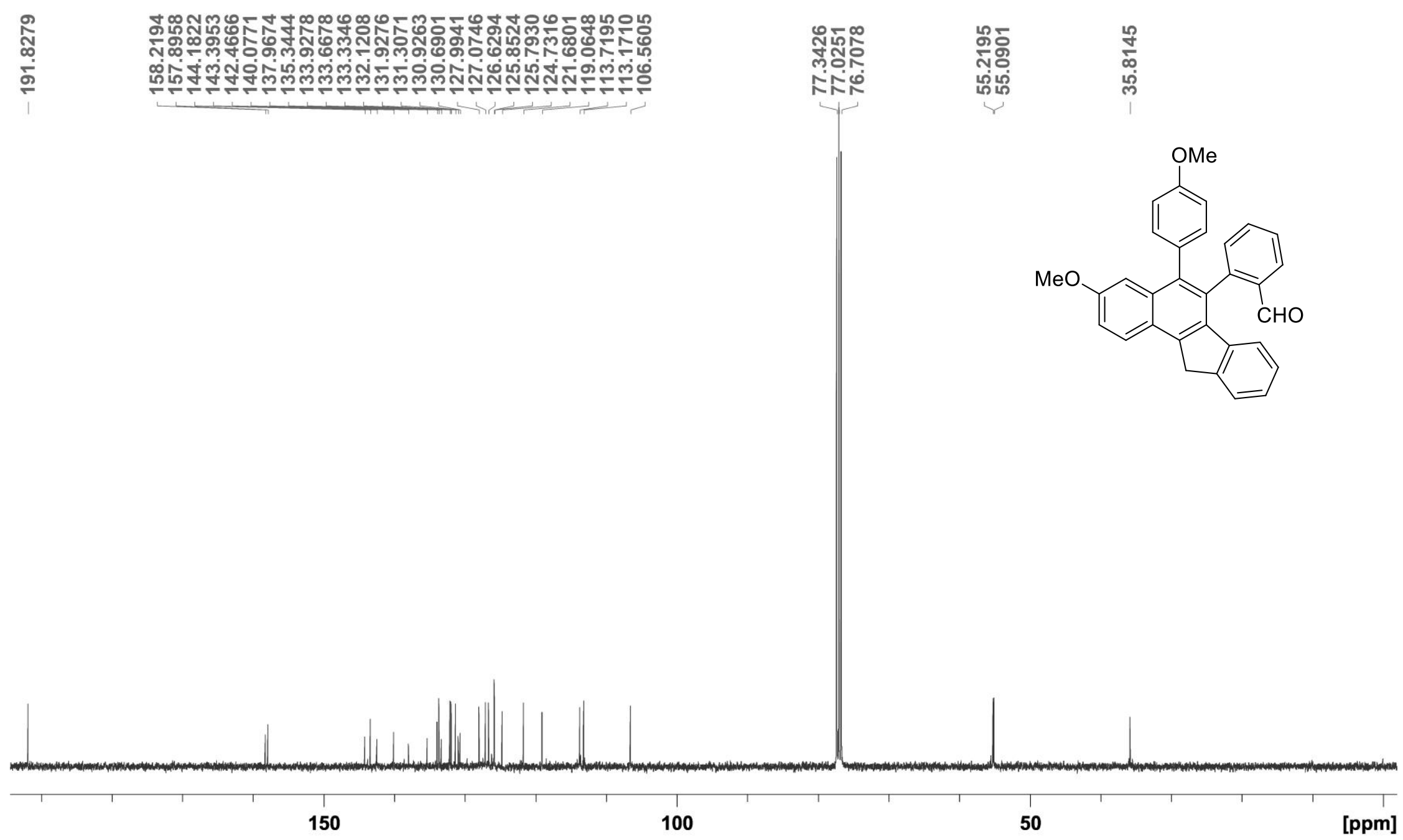

Figure S28. ${ }^{13} \mathrm{C}\left\{{ }^{1} \mathrm{H}\right\}$ NMR $\left(\mathrm{CDCl}_{3}, 100 \mathrm{MHz}\right)$ spectrum of compound 3a 


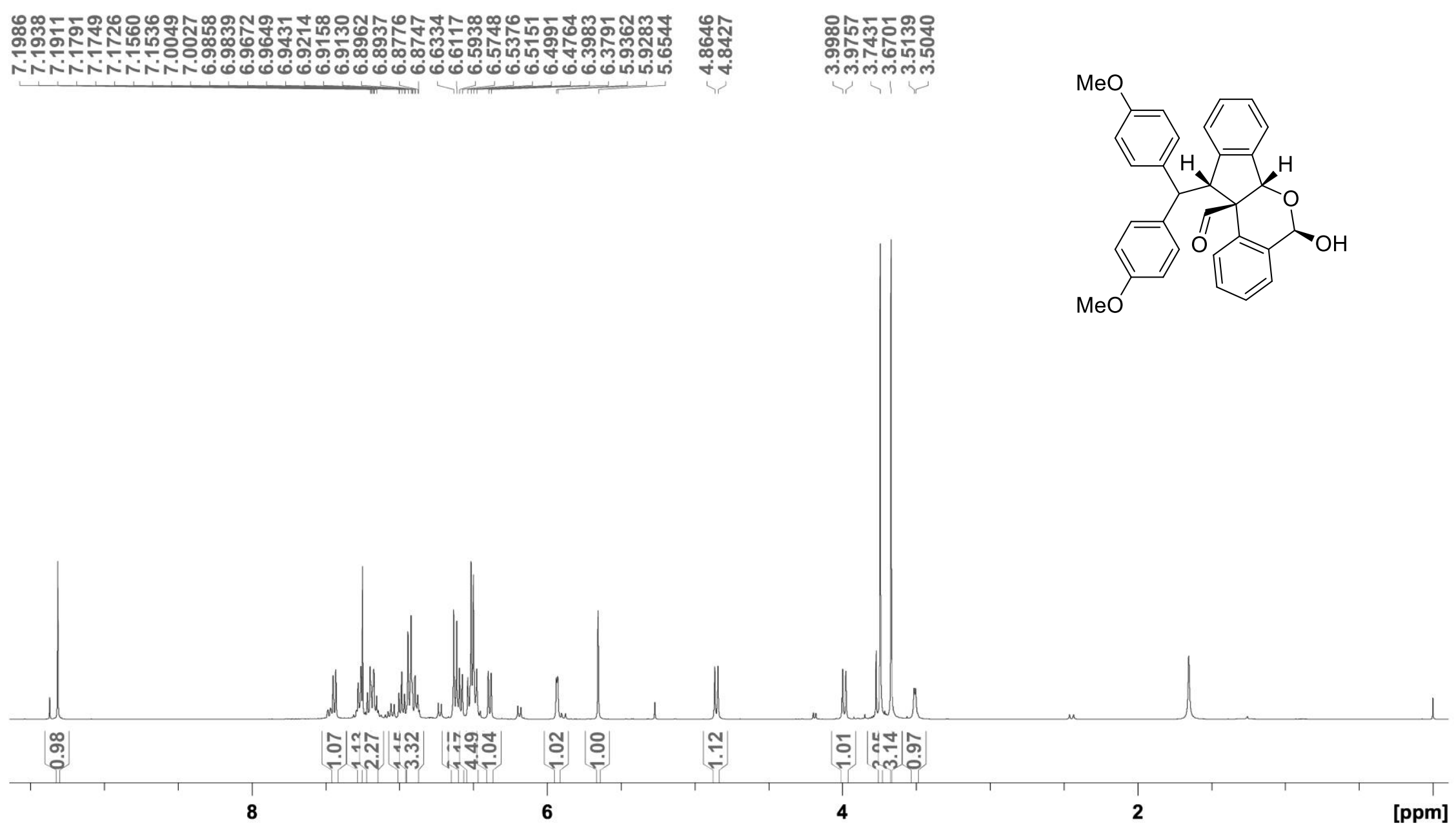

Figure S29. ${ }^{1} \mathrm{H} \mathrm{NMR}\left(\mathrm{CDCl}_{3}, 400 \mathrm{MHz}\right)$ spectrum of compound $\mathbf{3 b}$ 


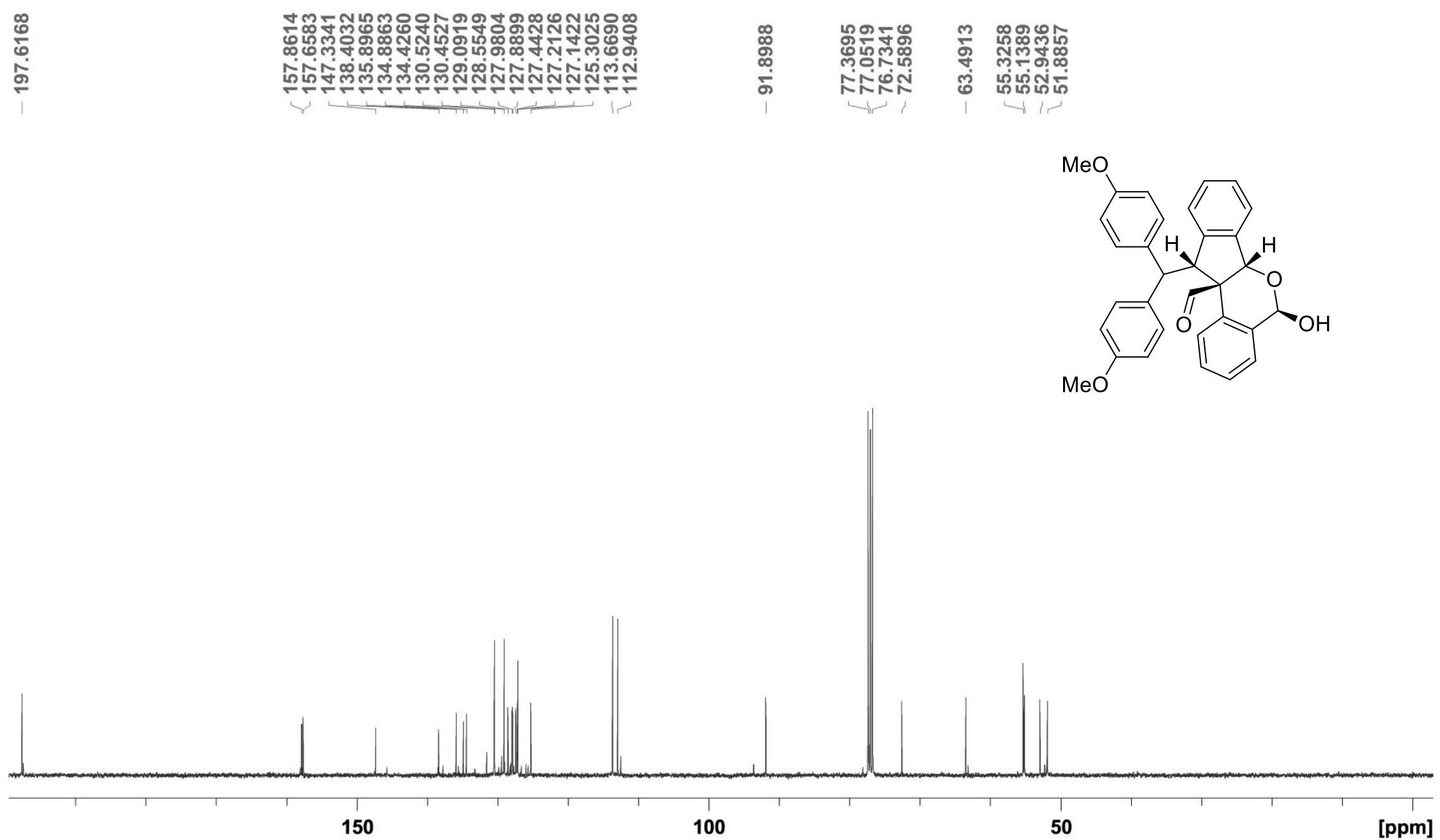

Figure $\mathrm{S} 30 .{ }^{13} \mathrm{C}\left\{{ }^{1} \mathrm{H}\right\} \mathrm{NMR}\left(\mathrm{CDCl}_{3}, 100 \mathrm{MHz}\right)$ spectrum of compound $\mathbf{3 b}$ 


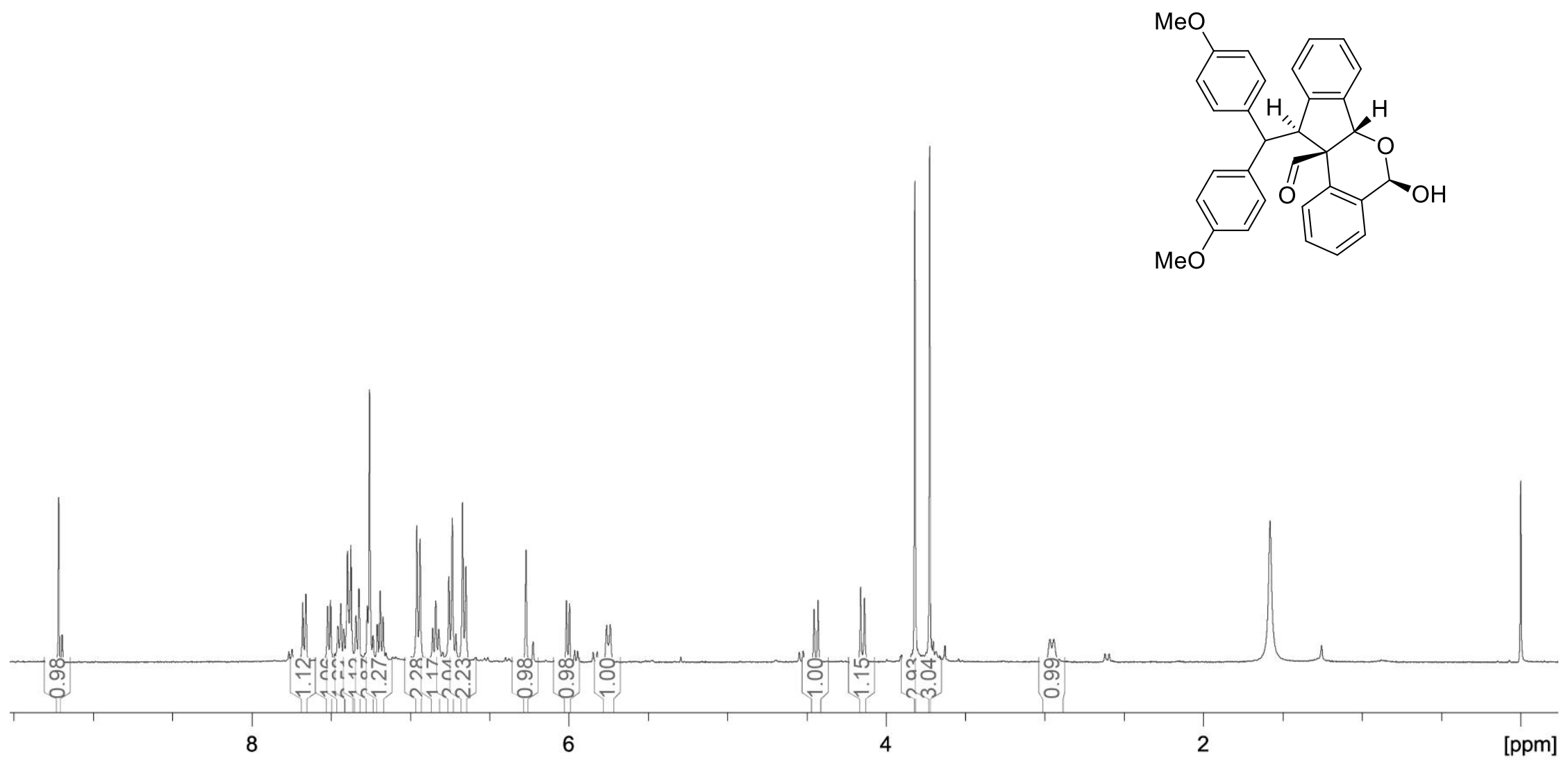

Figure S31. ${ }^{1} \mathrm{H} \mathrm{NMR}\left(\mathrm{CDCl}_{3}, 400 \mathrm{MHz}\right)$ spectrum of compound $3 \mathrm{c}$ 

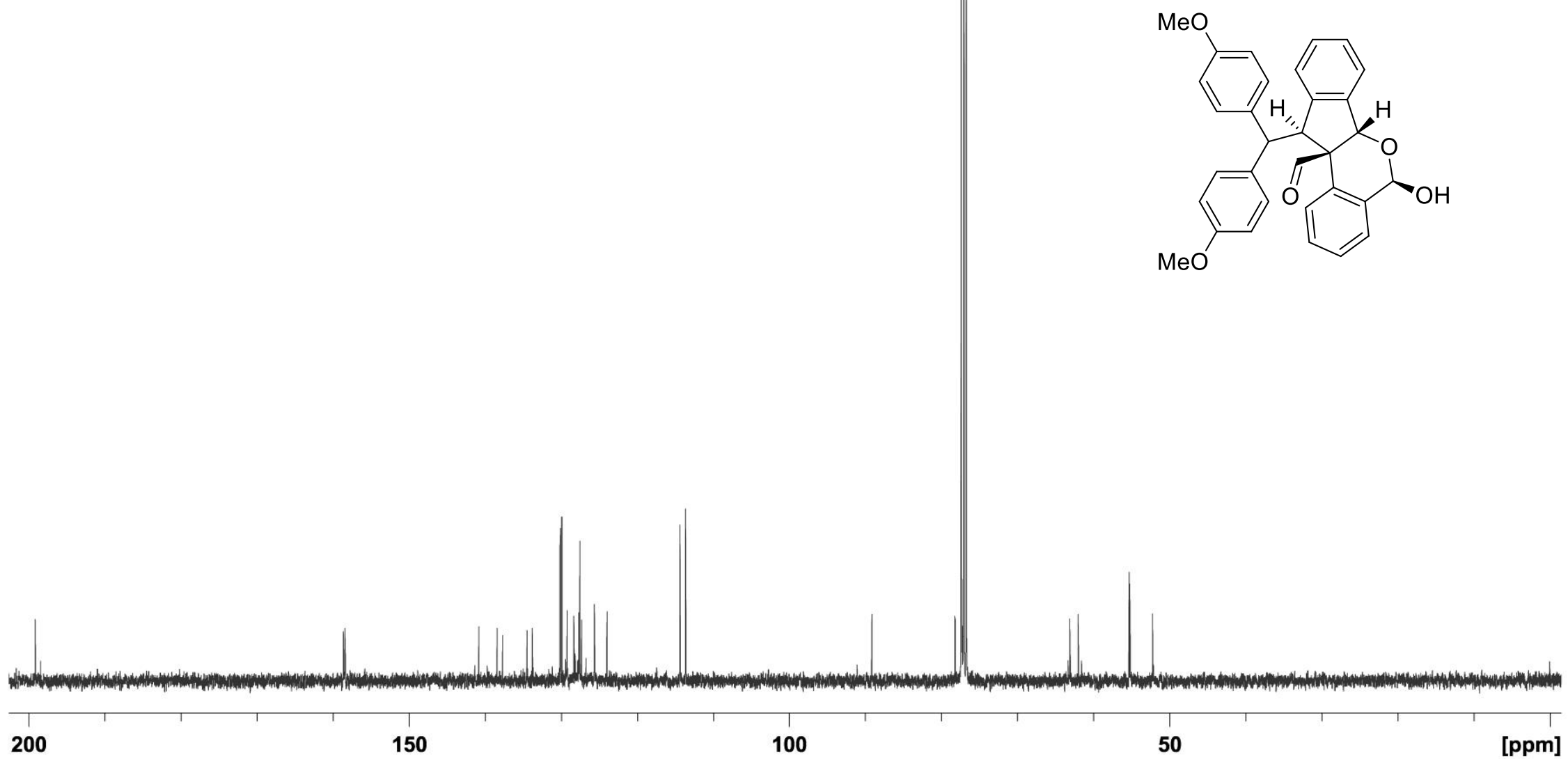

Figure $\mathrm{S} 32 .{ }^{13} \mathrm{C}\left\{{ }^{1} \mathrm{H}\right\}$ NMR $\left(\mathrm{CDCl}_{3}, 100 \mathrm{MHz}\right)$ spectrum of compound $\mathbf{3 c}$ 


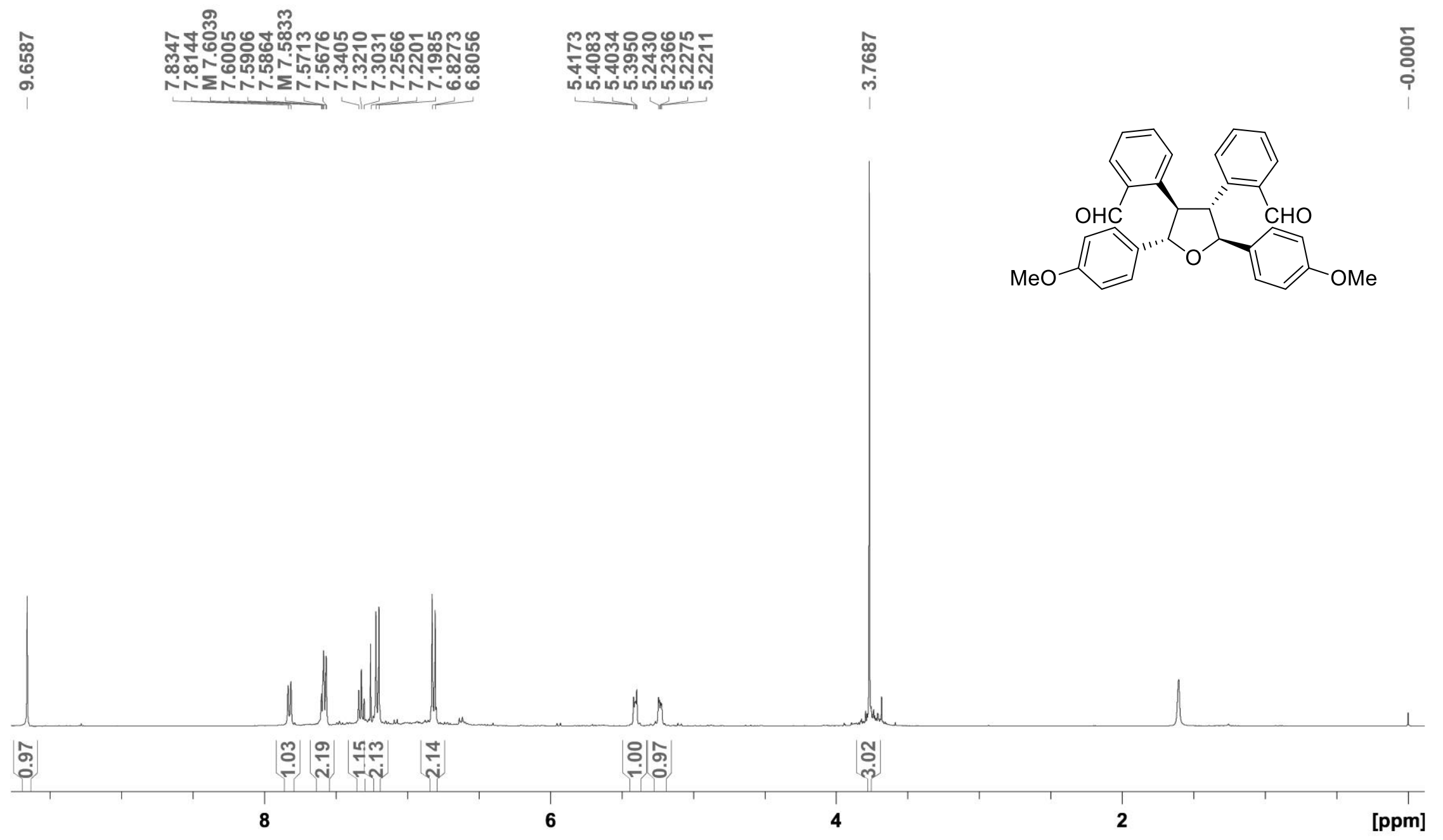

Figure S33. ${ }^{1} \mathrm{H} \mathrm{NMR}\left(\mathrm{CDCl}_{3}, 400 \mathrm{MHz}\right)$ spectrum of compound $\mathbf{3 d}$ 


\begin{tabular}{|c|c|c|c|c|c|}
\hline ্ֻণু & 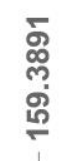 & 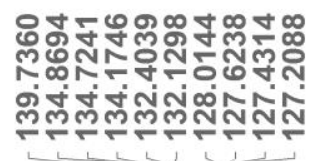 & 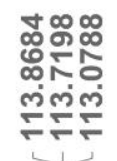 & 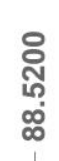 & 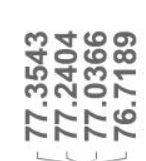 \\
\hline
\end{tabular}
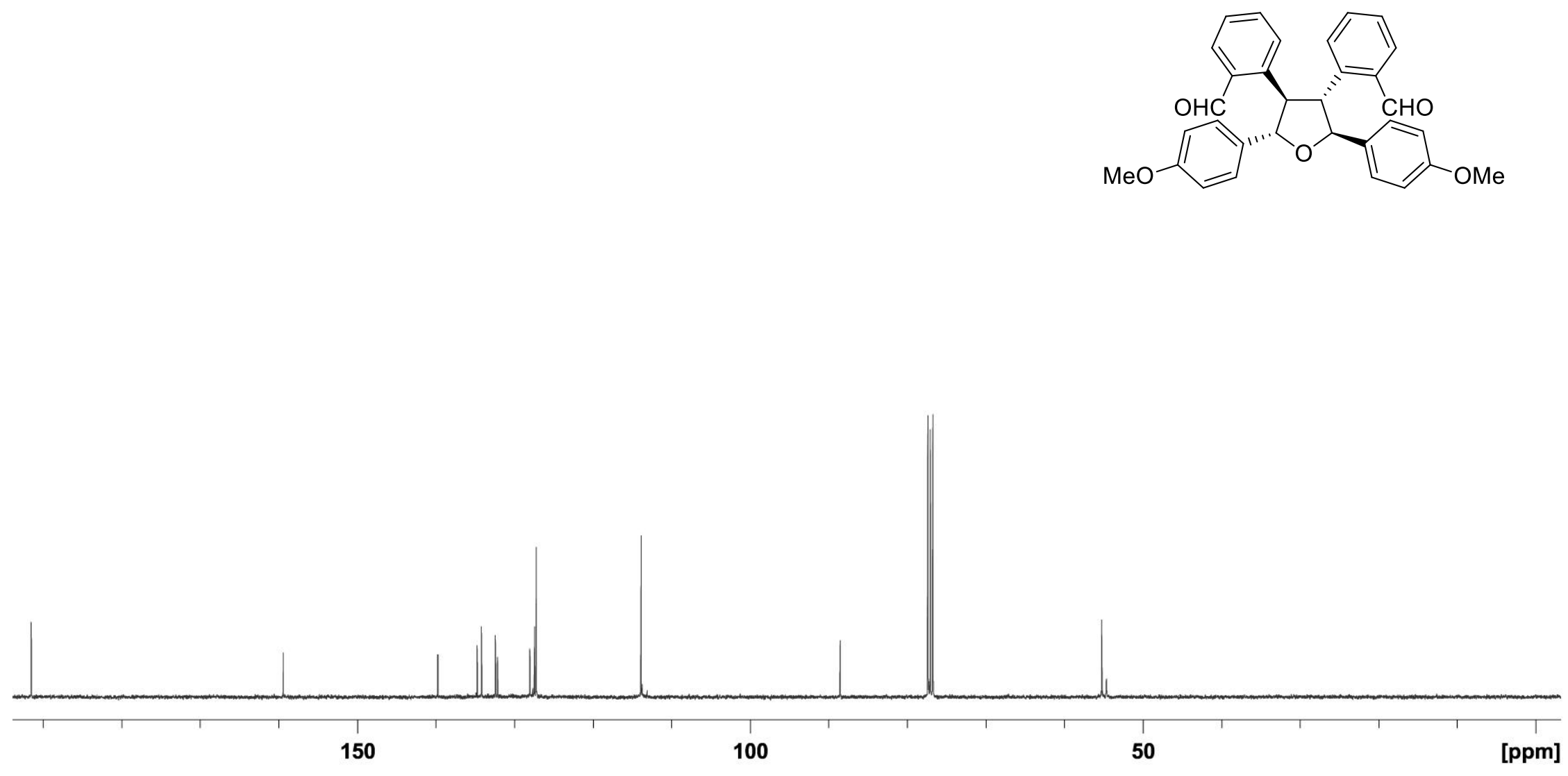

Figure $\mathrm{S} 34 .{ }^{13} \mathrm{C}\left\{{ }^{1} \mathrm{H}\right\} \mathrm{NMR}\left(\mathrm{CDCl}_{3}, 100 \mathrm{MHz}\right)$ spectrum of compound 3d 


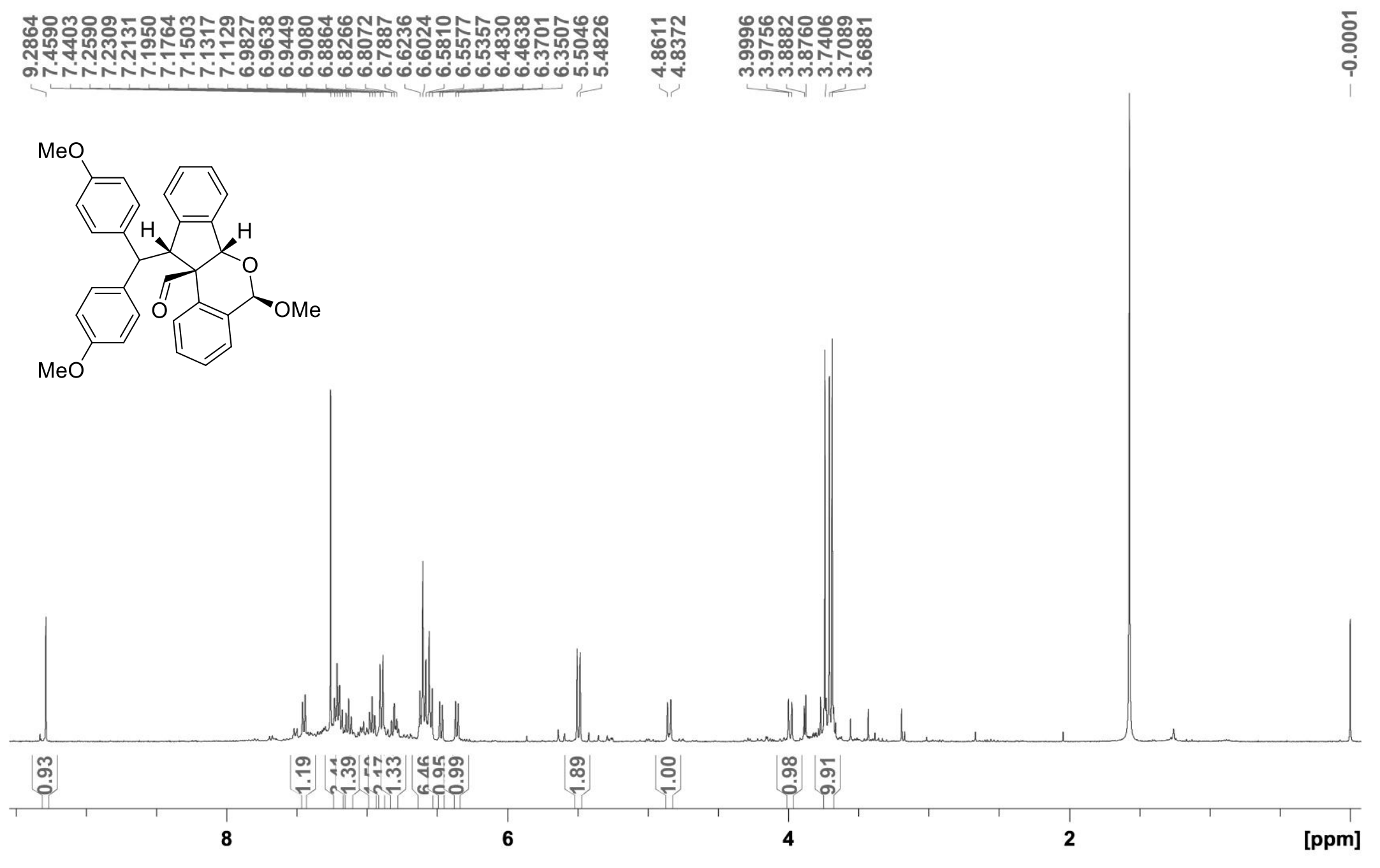

Figure S35. ${ }^{1} \mathrm{H}$ NMR $\left(\mathrm{CDCl}_{3}, 400 \mathrm{MHz}\right)$ spectrum of compound $4 \mathbf{a}$ 


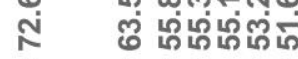

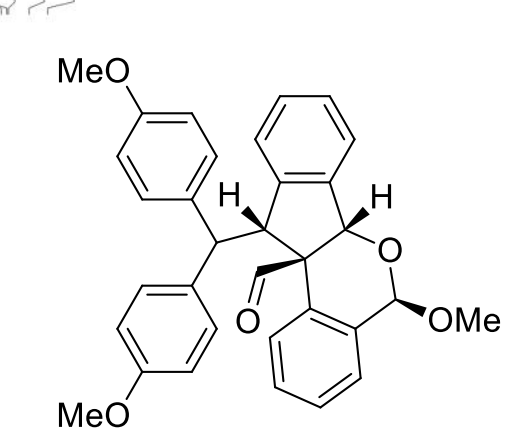

$\mathrm{MeO}$

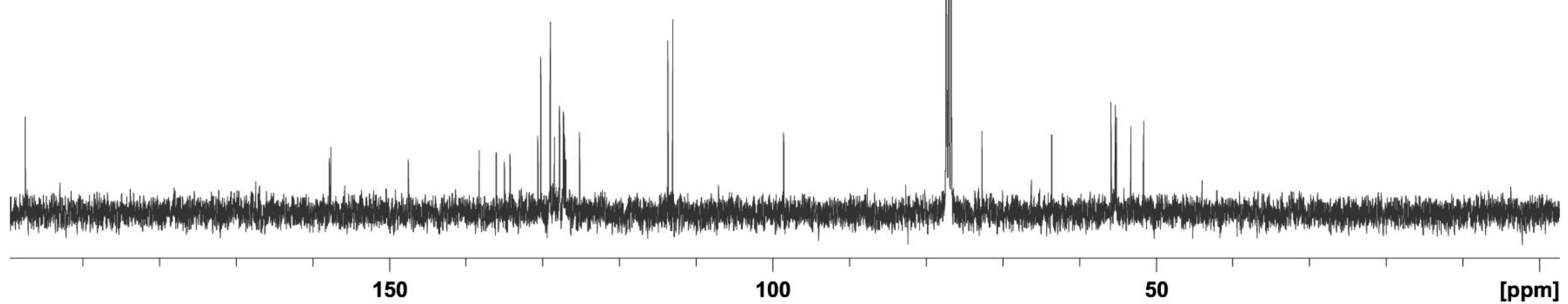

Figure S36. ${ }^{13} \mathrm{C}\left\{{ }^{1} \mathrm{H}\right\} \mathrm{NMR}\left(\mathrm{CDCl}_{3}, 100 \mathrm{MHz}\right)$ spectrum of compound $4 \mathbf{a}$ 


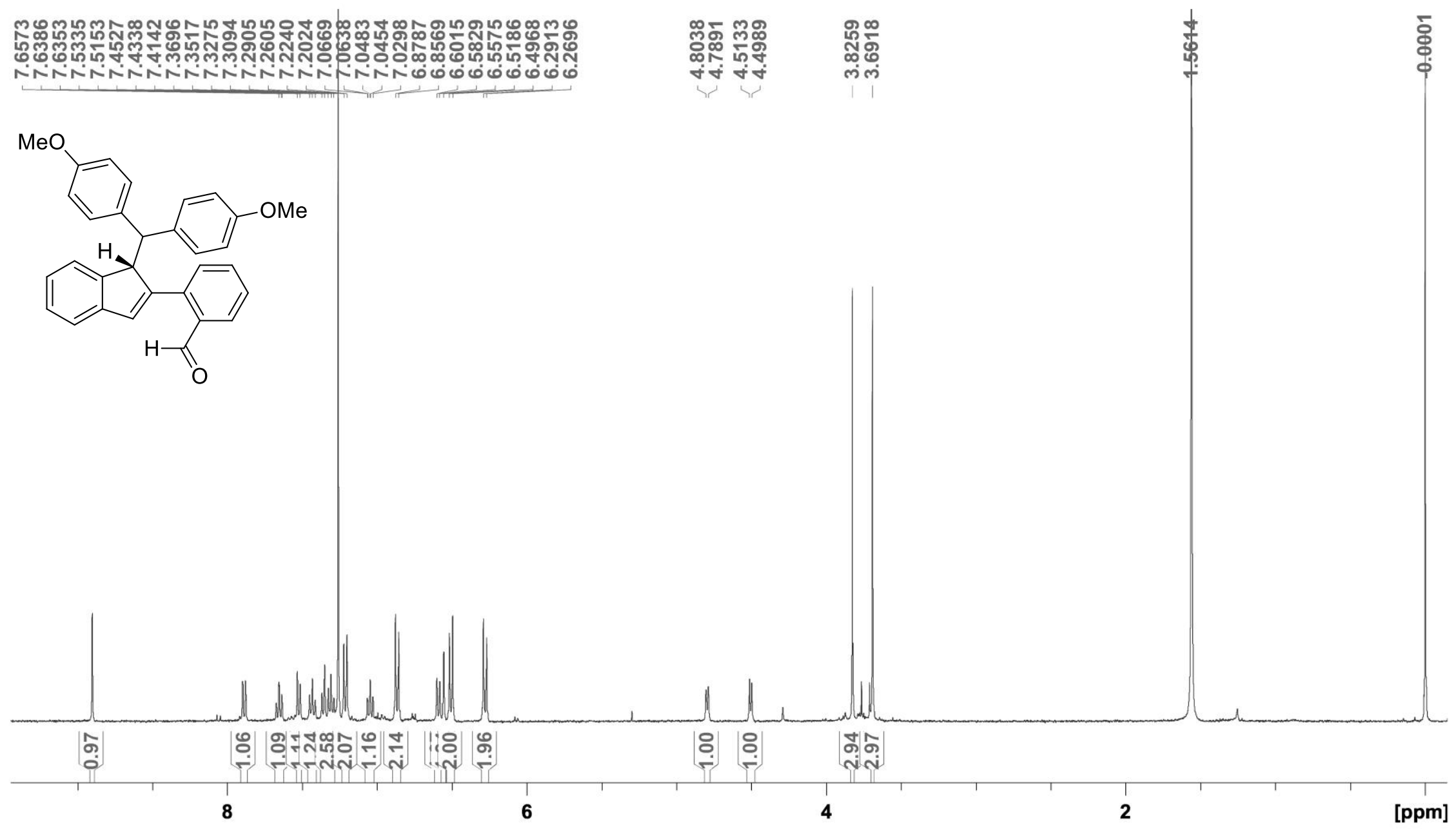

Figure S37. ${ }^{1} \mathrm{H}$ NMR $\left(\mathrm{CDCl}_{3}, 400 \mathrm{MHz}\right)$ spectrum of compound $\mathbf{5 a}$ 


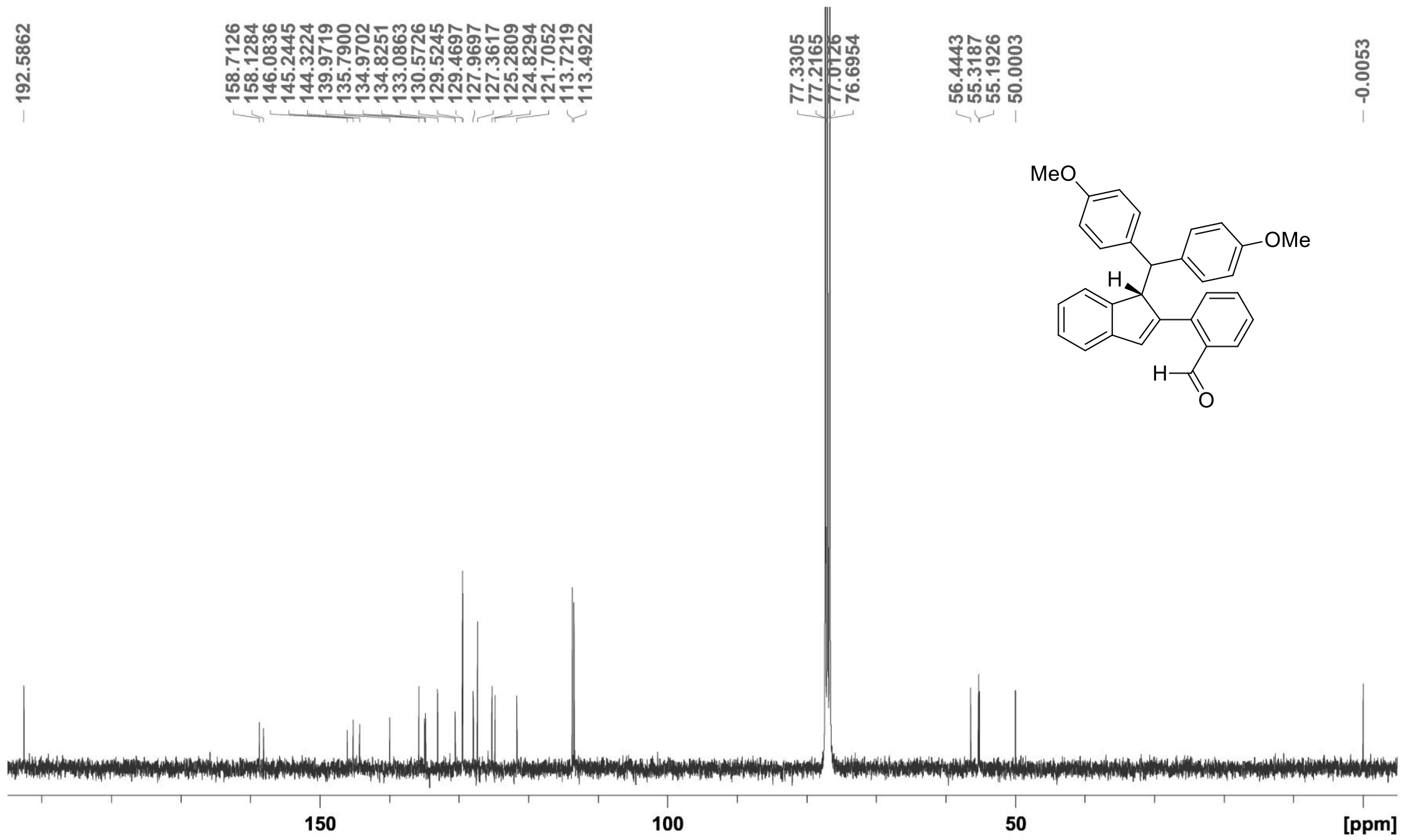

Figure S38. ${ }^{13} \mathrm{C}\left\{{ }^{1} \mathrm{H}\right\}$ NMR $\left(\mathrm{CDCl}_{3}, 100 \mathrm{MHz}\right)$ spectrum of compound $\mathbf{5 a}$ 


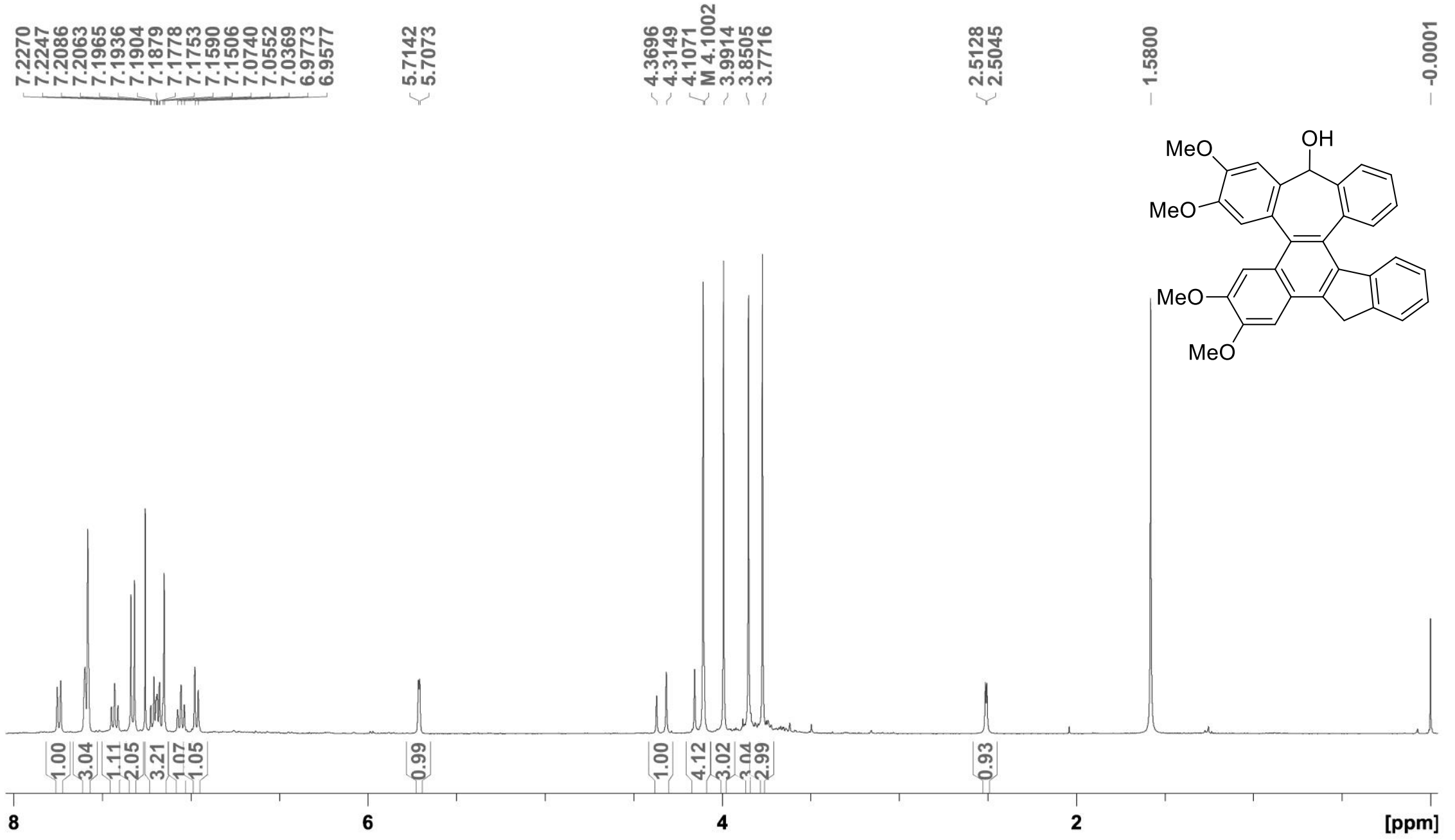

Figure S39. ${ }^{1} \mathrm{H} \mathrm{NMR}\left(\mathrm{CDCl}_{3}, 400 \mathrm{MHz}\right)$ spectrum of compound $\mathbf{6 a}$ 


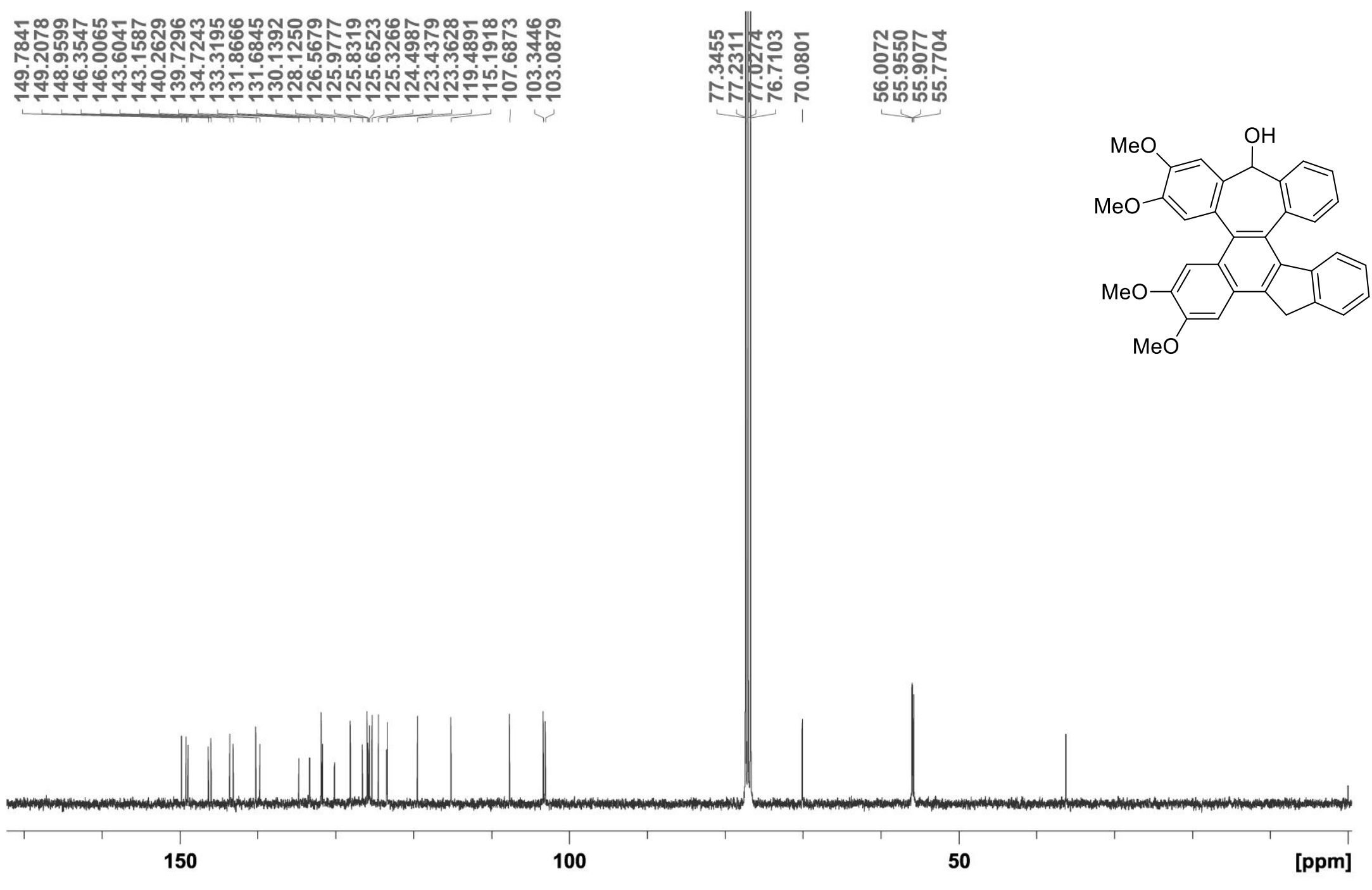

Figure $\mathrm{S} 40 .{ }^{13} \mathrm{C}\left\{{ }^{1} \mathrm{H}\right\} \mathrm{NMR}\left(\mathrm{CDCl}_{3}, 100 \mathrm{MHz}\right)$ spectrum of compound $6 \mathbf{a}$ 


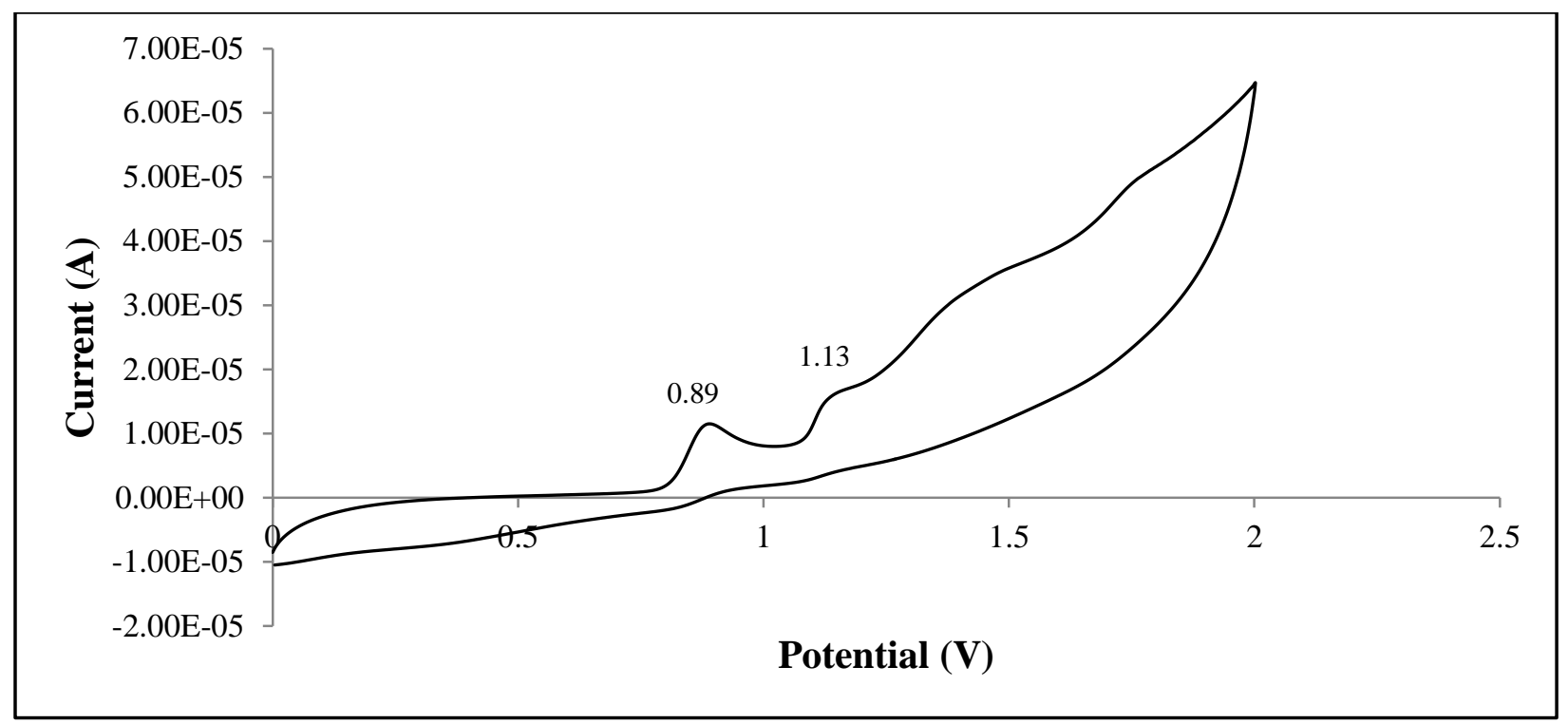

Figure S41: Cyclic voltammogram of 1 at Pt electrode in $\mathrm{MeCN} / 0.2 \mathrm{M} \mathrm{LiClO}_{4}$. E/V versus $\mathrm{Ag} / \mathrm{AgNO}_{3}$, sweep rate $=0.2 \mathrm{~V} / \mathrm{s}$.

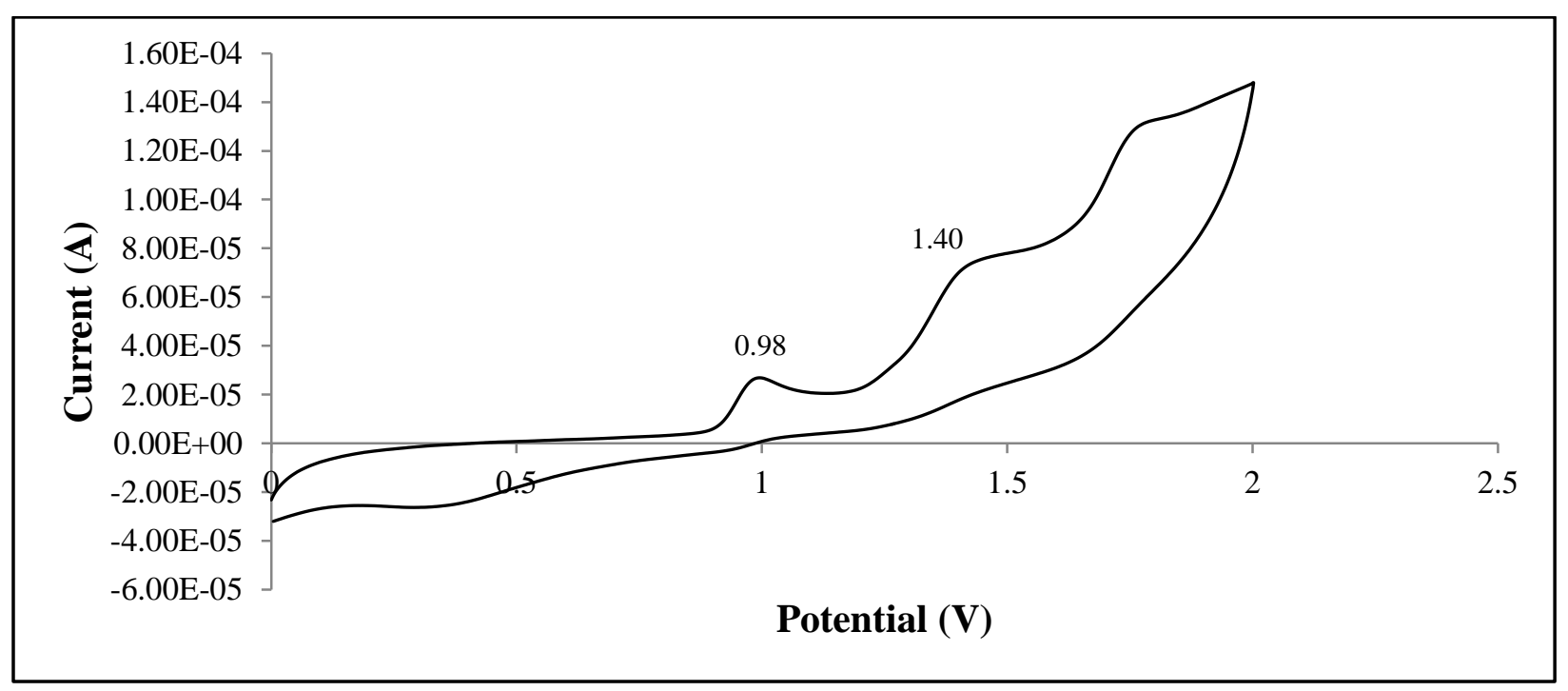

Figure S42: Cyclic voltammogram of 3 at Pt electrode in $\mathrm{MeCN} / 0.2 \mathrm{M} \mathrm{LiClO}_{4}$. E/V versus $\mathrm{Ag} / \mathrm{AgNO}_{3}$, sweep rate $=0.2 \mathrm{~V} / \mathrm{s}$. 
X-ray Crystallographic Analysis of 3a, 3b and 6a. Suitable crystals were obtained from slow evaporation in $\mathrm{MeOH} / \mathrm{CH}_{2} \mathrm{Cl}_{2}$. The crystals were observed under a microscope with a polarizer attached. A single crystal was chosen (based on shape and the ability to transmit and extinguish polarized light completely) and cut such that each dimension $(\max \times \operatorname{med} \times \min )$ does not exceed $0.5 \mathrm{~mm}$. The crystal was then fixed with an adhesive (Cargille ${ }^{\mathrm{TM}}$ immersion oil, Type $\mathrm{NVH}$ ) onto a glass fiber that is in turn glued into a 'copper pip' that fits into the well at the top of the goniometer head. The goniometer head was then attached to the $\phi$ circle of the diffractometer. The crystal was optically adjusted so that its center does not move when it was rotated. A stream of $\mathrm{N}_{2}$ gas cooled to $100 \mathrm{~K}$ was used for low temperature diffraction experiments. All data were collected on a Rigaku Oxford (formerly Agilent Technologies) SuperNova Dual diffractometer with $\mathrm{Cu} \mathrm{K} \alpha(\lambda=1.54184 \AA)$. The structures were solved by direct methods (SHELXS-2014) and refined with full-matrix least-squares on $F^{2}$ (SHELXL2014). All non-hydrogen atoms were refined anisotropically, and all hydrogen atoms were placed in idealized positions and refined as riding atoms with the relative isotropic parameters.

Crystallographic data for $\mathbf{3 a}, \mathbf{3 b}$, and $\mathbf{6 a}$ have been deposited with the Cambridge Crystallographic Data Centre. Copies of the data can be obtained, free of charge, on application to the Director, CCDC, 12 Union Road, Cambridge CB2 1EZ, UK (fax: +44 (0)1223-336033, or e-mail: $\underline{\text { deposit@ ccdc.cam.ac.uk). }}$ 

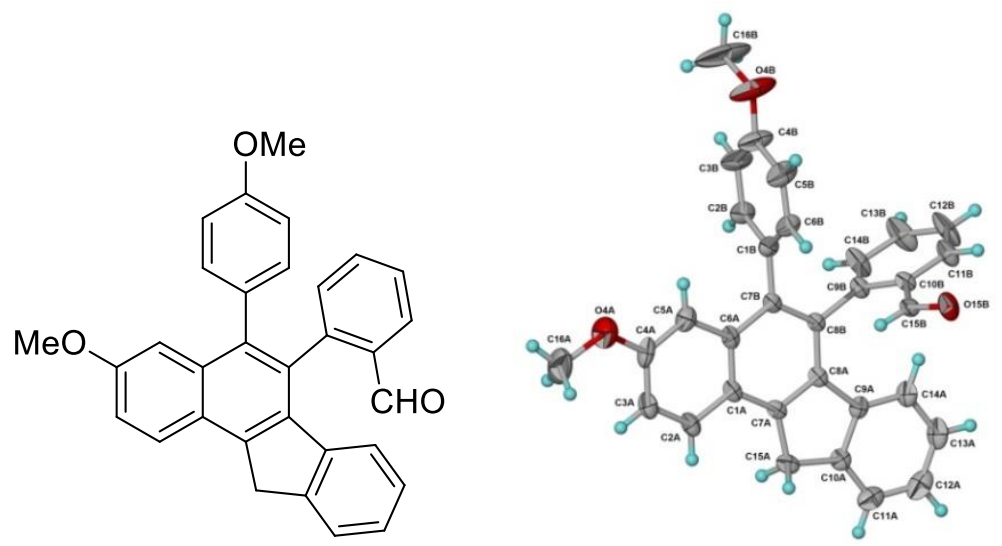

Figure S43: X-ray crystal structure of 3a. Thermal ellipsoids are shown at the 50\% probability level.

\begin{tabular}{ll}
\hline Table S1: Crystal data and structure refinement for 3a. \\
\hline Empirical formula & $\mathrm{C}_{32} \mathrm{H}_{24} \mathrm{O}_{3}$ \\
Molecular formula & $\mathrm{C}_{32} \mathrm{H}_{24} \mathrm{O}_{3}$ \\
Molecular weight, $M_{r}$ & 456.51 \\
Melting point & $181-183{ }^{\circ} \mathrm{C}$ \\
Temperature during diffraction experiment, $T$ & $296 \mathrm{~K}$ \\
X-ray source & Mo $K_{\alpha}$ \\
Crystal system & Triclinic \\
Space group & $P-1$ \\
$a$ & $10.8576(3) \AA$ \\
$b$ & $13.0152(4) \AA$ \\
$c$ & $17.4505(5) \AA$ \\
$\alpha$ & $104.015(2)^{\circ}$ \\
$\beta$ & $97.067(2)^{\circ}$ \\
$\gamma$ & $96.925(2)^{\circ}$ \\
Volume, $V$ & $2345.28(12) \AA^{3}$ \\
Number of molecule per unit cell, $Z$ & 4 \\
Density (calcd) & $1.293 \mathrm{mg} / \mathrm{mm}^{3}$ \\
$F(000)$ & 960 \\
Crystal size & $0.42 \times 0.10 \times 0.02 \mathrm{~mm}$ \\
$2 \theta$ range for data collection & 2.436 to $52.776^{\circ}$ \\
Index ranges & $-13 \leq \mathrm{h} \leq 13,-16 \leq \mathrm{k} \leq 16,-21 \leq 1 \leq 21$ \\
Reflections collected & 20795 \\
Independent reflections & $9561\left[R_{\text {int }}=0.0931, R_{\text {sigma }}=0.0513\right]$ \\
Data/restraints/parameters & $9561 / 0 / 634$ \\
Goodness-of-fit on $F^{2}$ & 1.287 \\
Final R indexes $[I \geq 2 \sigma(I)]$ & $R_{1}=0.1297, w R_{2}=0.3583$ \\
Final R indexes [all data $]$ & $R_{1}=0.2121, w R_{2}=0.4175$ \\
Largest diff. peak/hole / e $\AA^{-3}$ & $1.42 /-0.77$ \\
CCDC deposition number & 1896452 \\
\hline &
\end{tabular}



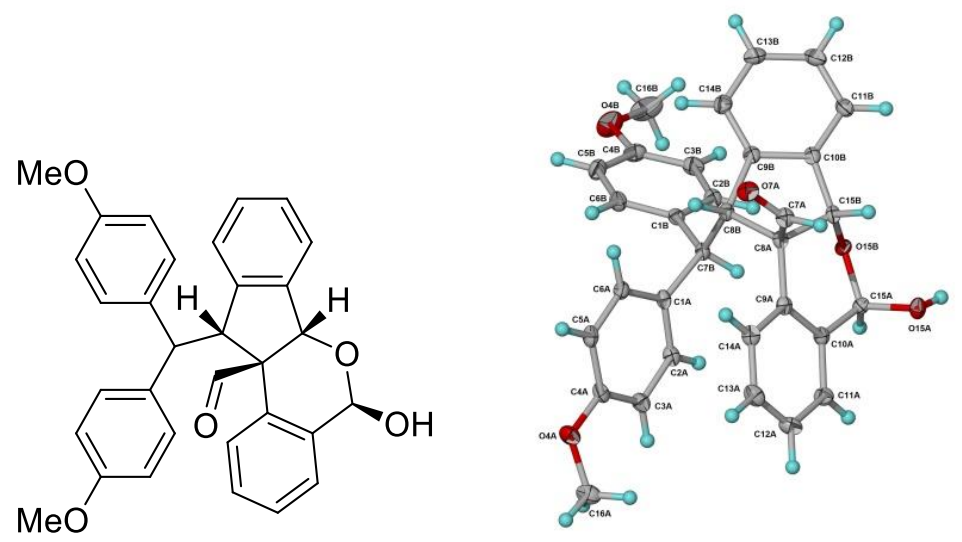

Figure S44: X-ray crystal structure of $\mathbf{3 b}$. Thermal ellipsoids are shown at the 50\% probability level.

Table S2: Crystal data and structure refinement for $3 \mathrm{~b}$.

\begin{tabular}{|c|c|}
\hline Empirical formula & $\mathrm{C}_{32} \mathrm{H}_{28} \mathrm{O}_{5}$ \\
\hline Molecular formula & $\mathrm{C}_{32} \mathrm{H}_{28} \mathrm{O}_{5}$ \\
\hline Molecular weight, $M_{r}$ & 492.54 \\
\hline Melting point & $202-204{ }^{\circ} \mathrm{C}$ \\
\hline Temperature during diffraction experiment, $T$ & $100 \mathrm{~K}$ \\
\hline X-ray source & Mo $K_{\alpha}$ \\
\hline Crystal system & Monoclinic \\
\hline Space group & $P 2{ }_{1} / n$ \\
\hline$a$ & $12.3322(6) \AA$ \\
\hline$b$ & $9.6323(5) \AA$ \\
\hline$c$ & $21.0939(10) \AA$ \\
\hline$\alpha$ & $90^{\circ}$ \\
\hline$\beta$ & $91.129(3)^{\circ}$ \\
\hline$\gamma$ & $90^{\circ}$ \\
\hline Volume, $V$ & $2505.2(2) \AA^{3}$ \\
\hline Number of molecule per unit cell, $Z$ & 4 \\
\hline Density (calcd) & $1.306 \mathrm{mg} / \mathrm{mm}^{3}$ \\
\hline$F(000)$ & 1040 \\
\hline Crystal size & $0.55 \times 0.23 \times 0.14 \mathrm{~mm}$ \\
\hline $2 \theta$ range for data collection & 3.794 to $56.946^{\circ}$ \\
\hline Index ranges & $-16 \leq \mathrm{h} \leq 15,-12 \leq \mathrm{k} \leq 12,-28 \leq 1 \leq 28$ \\
\hline Reflections collected & 24673 \\
\hline Independent reflections & $6279\left[R_{\text {int }}=0.0513, R_{\text {sigma }}=0.0539\right]$ \\
\hline Data/restraints/parameters & $6279 / 0 / 337$ \\
\hline Goodness-of-fit on $F^{2}$ & 1.022 \\
\hline Final $\mathrm{R}$ indexes $[I \geq 2 \sigma(I)]$ & $R_{1}=0.0469, w R_{2}=0.1032$ \\
\hline Final $\mathrm{R}$ indexes [all data] & $R_{1}=0.0721, w R_{2}=0.1154$ \\
\hline Largest diff. peak/hole / e $\AA^{-3}$ & $0.27 /-0.25$ \\
\hline CCDC deposition number & 1896453 \\
\hline
\end{tabular}



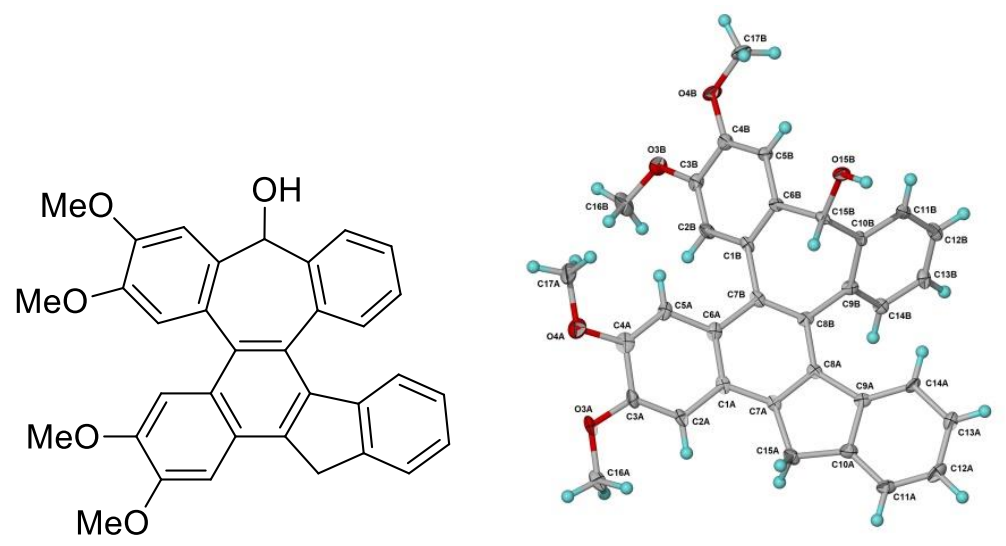

Figure S45: X-ray crystal structure of 6 a. Thermal ellipsoids are shown at the 50\% probability level.

Table S3: Crystal data and structure refinement for 6 .

Empirical formula

Molecular formula

Molecular weight, $M_{r}$

Melting point

Temperature during diffraction experiment, $T$

$\mathrm{X}$-ray source

Crystal system

Space group

$a$

$b$

$c$

$\alpha$

$\beta$

$\gamma$

Volume, $V$

Number of molecule per unit cell, $Z$

Density (calcd)

$F(000)$

Crystal size

$2 \theta$ range for data collection

Index ranges

Reflections collected

Independent reflections

Data/restraints/parameters

Goodness-of-fit on $F^{2}$

Final $\mathrm{R}$ indexes $[I \geq 2 \sigma(I)]$

Final $\mathrm{R}$ indexes [all data]

Largest diff. peak/hole / e $\AA^{-3}$

$\mathrm{CCDC}$ deposition number
$\mathrm{C}_{34} \mathrm{H}_{28} \mathrm{O}_{5}$

$\mathrm{C}_{34} \mathrm{H}_{28} \mathrm{O}_{5}$

516.56

$195-197{ }^{\circ} \mathrm{C}$

$100 \mathrm{~K}$

Mo $K_{\alpha}$

Monoclinic

$P 2_{1} / c$

14.3284(6) А

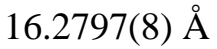

21.9001(10)

$90^{\circ}$

$92.092(4)^{\circ}$

$90^{\circ}$

5105.1(4) $\AA^{3}$

8

$1.344 \mathrm{mg} / \mathrm{mm}^{3}$

2176

$0.4 \times 0.2 \times 0.1 \mathrm{~mm}$

5.690 to $60.716^{\circ}$

$-19 \leq \mathrm{h} \leq 19,-22 \leq \mathrm{k} \leq 21,-29 \leq 1 \leq 27$

37055

$13524\left[R_{\text {int }}=0.1069, R_{\text {sigma }}=0.0982\right]$

$13524 / 0 / 713$

1.101

$R_{1}=0.2366, w R_{2}=0.5669$

$R_{1}=0.2598, w R_{2}=0.5761$

$1.20 /-0.87$

1896454 